Federal Reserve Bank of Minneapolis

Research Department Staff Report 437

November 2009

\title{
The Economic Performance of Cartels: Evidence from the New Deal U.S. Sugar Manufacturing Cartel, 1934-74*
}

\author{
Benjamin Bridgman \\ Bureau of Economic Analysis
}

\section{Shi Qi}

University of Minnesota

James A. Schmitz, Jr.

Federal Reserve Bank of Minneapolis

\begin{abstract}
We study the U.S. sugar manufacturing cartel that was created during the New Deal. This was a legal-cartel that lasted 40 years (1934-74). As a legal-cartel, the industry was assured widespread adherence to domestic and import sales quotas (given it had access to government enforcement powers). But it also meant accepting government-sponsored cartel-provisions. These provisions significantly distorted production at each factory and also where the industry was located. These distortions were reflected in, for example, a declining industry recovery rate, that is, the pounds of white sugar produced per ton of beets. It declined from about 310 pounds in 1934 to 240 pounds in 1974. The cartel provisions also distorted the location of industry. For example, it kept production in California and the Far West. Since the cartel ended in 1974, California's share of sugar production has dropped dramatically.
\end{abstract}

\footnotetext{
*This paper originally circulated under the title "Does Regulation Reduce Productivity? Evidence From Regulation of the U.S. Beet-Sugar Manufacturing Industry During the Sugar Acts, 1934-74." We would like to thank Sam Kortum for his very helpful comments as a discussant at the Minnesota Micro Conference in October 2006. We thank Brian Holmes for excellent research assistance. We would also like to thank the large number of people in the industry that provided help, especially Charles Schmalz, who worked for both the Utah \& Idaho and Amalgamated Sugar Companies; Dennis Costesso of Amalgamated Sugar Company; and James Horvath and Dave Malmskog from the American Crystal Sugar Company. Finally, we thank Wayne Thompson at the National Agricultural Library and the librarians at the Federal Reserve Bank of Minneapolis Research Library, including Terry Maroney and Brooke Tosi, who helped us tremendously. The views expressed herein are those of the authors and not necessarily those of the Federal Reserve Bank of Minneapolis, the Federal Reserve System, the U.S. Bureau of Economic Analysis or the U.S. Department of Commerce.
} 


\section{Introduction}

Research on cartels has primarily focused on their ability to raise price. Though cartels may have important impacts on productivity and the allocation of resources in industry, little is known about them. ${ }^{1}$ To learn more, we study the performance of the New-Deal sugar manufacturing cartel that existed from 1934-74. We'll show that the cartel led to major distortions in both how sugar was produced at a given factory, and in where the industry was located.

As with other New-Deal cartels, this was a legal-cartel, created with the encouragement and under the supervision of the U.S. government. While most New-Deal cartels lasted only a few years (as the Supreme Court ruled them unconstitutional), this cartel survived 40 years. That the cartel operated with the consent and enforcement powers of the U.S. government had two major consequences. First, whatever cartels rules or provisions were established, it was clear that there would be widespread adherence to them (since the cartel had access to the government's enforcement powers). Second, it meant that the industry was accepting the government as a "partner" in structuring the cartel.

The initial cartel plan was drafted by the industry (including representatives of both factories and farmers). Its major provisions were for limiting sugar sales. There were quotas on foreign sugar imports. Regarding domestic production, no new firms were allowed to enter the industry, and existing firms were given sales quotas. The goal of these provisions, obviously, was to raise domestic sugar prices. But the plan was rejected by the government for not providing enough benefits to certain segments of the industry, such as beet and cane farmers.

The industry subsequently drafted a compromise-plan that was acceptable to the government. The second plan included the provisions to limit sugar sales contained in the initial plan. It also included provisions that directly benefited farmers. First, there was to be no entry of new farmers.

\footnotetext{
${ }^{1}$ For a review of the literature on cartels, see Levenstein and Suslow (2006). There they emphasize "perhaps the least studied, but most important issues are the effect cartels have on investment and productivity." (p. 84)
} 
Incumbent farmers were given an allotment (i.e., quota) of acres to grow sugar crops, and this was tied to the farmer's initial (i.e., pre-cartel) acreage. Second, for agreeing to abide by the government allotments, farmers were given subsidies based on their production. These subsidies were funded by taxing the output of sugar factories. And, lastly, the second plan gave the government authority to intervene in the contract negotiations between farmers and factories that set prices for crops. In summary, then, the second plan had four major provisions. It had the provisions in the original plan regarding limiting sugar sales, and three new ones: no entry of farmers (with allotments for incumbents), the tax/subsidy scheme, and a government role in contracting.

The provisions in the original plan that limited sugar sales, and hence led to higher sugar prices, led to usual types of distortions (e.g., too little consumption and a loss in consumer surplus). On the production side, we'll show raising prices distorted production at each factory, in particular, it led to lower crop quality (where quality is measured by the sugar content of the beets and sugarcane). The new provisions were also a force for lower crop quality, hence compounding the distortions at each factory. In addition, the new provisions distorted the location of the industry. Hence, accepting the government as a partner came at a price: it compounded distortions to production at each factory, and distorted where factories were located.

Consider the distortions caused by the new provisions. First, consider the subsidies. Before the cartel, industry revenue was derived from selling sugar that had been extracted from beets in the factory. That is, the industry product was refined white sugar in bags. The subsidy to farmers in the cartel agreement was based on the amount of sugar in the beets before extraction. Hence, the industry now had a source of revenue (a big one, see below) that was not based on the amount of refined sugar it produced. Obviously, before the cartel, when decisions were made on how to grow beets, a careful eye was kept on how the growing decisions influenced the ease with which sugar could be extracted from the beets in the factory. With the subsidy, with a large payment made for how much sugar was in the beets before extraction, there was now less concern about ease of 
extraction. Obviously, this was a distortion to efficient production.

Having high quality beets (those with high sugar content, those "dense" in sugar) made extraction less costly at the factory (in a sense formalized below). Hence, the subsidy, by lessening incentives for ease of extraction, was a force for lower quality beets.

Giving farmers an acreage allotment was also a force for lower quality. If these allotments were binding, so that farmers wanted to grow more sugar but could not expand acreage, then farmers would substitute other inputs for land like materials (such as water and fertilizer). It's well known that more materials on an acre will increase sugar production (tons of beets multiplied by the sugar content of the beets) but at the cost of lower beet quality. ${ }^{2}$

Prohibiting the entry of farmers distorted the location of the industry. In the first cartel plan, firms were given sales quotas, but no restrictions on where production could occur. But in the second plan, a firm could not produce its quota in a different location since there would be no farmers there to supply beets - entry of farmers was prohibited. Hence, if over the period 1934-74 there were forces making one area more attractive than another to grow beets and make sugar, then the cartel provisions would distort industry location (since the industry could not move). Note that here the distortion would become obvious after the cartel was abandoned, when we saw the industry move its location after the cartel's provisions were removed.

There is strong evidence that the cartel led to both types of distortions, at the factory level, and in the location of industry. Again, first consider the distortion at the factory. In this paper, in looking at the evidence, we focus on the beet-sugar manufacturing segment of the industry. ${ }^{3}$ U.S. average beet quality shows a fairly close relationship with the cartel: it was increasing before the cartel, then fell during the cartel, and has risen since the cartel ended (see Figure 5). Another measure of factory performance is the extraction rate, that is, the fraction of sugar in the beets

\footnotetext{
${ }^{2}$ Below we'll discuss how giving the government a role in contract negotiations was also a force for low quality beets.

${ }^{3}$ We have collected extensive information on the raw cane sugar industry as well. Similar patterns are found in this industry but to limit the size of this paper we do not present these results.
} 
that is extracted as white sugar. As argued below, the cartel provisions should have decreased the extraction rate as well. The extraction rate also has a fairly close relationship with the cartel period (again, see Figure 5).

Another industry statistic is the recovery rate, which is simply the product of beet quality and the extraction rate. It equals the number of pounds of white sugar recovered from a ton of beets. ${ }^{4}$ When we examine factory data below, this statistic is typically more widely available than are the other two, that is, beet quality and the extraction rate. The U.S. average recovery rate was about 310 pounds of sugar per ton of beets in 1934. It fell throughout the cartel period to about 240 pounds in 1974 (see Figure 4), and has climbed steadily since the cartel ended.

As the theory suggests, then, beet quality and the recovery rate fell during the cartel. To further "test" whether it was the cartel provisions that led to these declines, we examine what was akin to a "natural" experiment in this industry. When the cartel was established in 1934, there were differences across regions in the extent to which the industry could manipulate the quality of beets. In areas with irrigated water, farmers had much more control over beet quality than in areas with no irrigated water. Hence, the cartel should have had a much bigger impact on quality and recovery rates in the irrigated regions as opposed to non-irrigated regions.

In terms of regions, California offered beet farmers the greatest opportunity to manipulate beet quality: most of its land was irrigated, and many farms were in arid regions (another characteristic allowing control of quality). Average beet quality in California was significantly above the U.S. average before the cartel (18 versus 16 percent). During the cartel, beet quality in California fell much more than the U.S. average, so that by the end of the 1960s, the average in California was below the U.S. average (see Figure 6).

To further explore differences in regions, we have collected the records of the major U.S. beet

\footnotetext{
${ }^{4}$ For example, if a factory processed a ton of beets that contained 20 percent sugar, and achieved a 95 percent extraction rate, then the recovery rate would be $2000 \times(.2) \times(.95)=380$ pounds of sugar.
} 
sugar producing companies in the twentieth century, and for many companies we have the records of their individual factories. We show that the recovery rate was increasing in factories in both the irrigated and non-irrigated regions (and at roughly the same rate) before the cartel. Then, with the cartel, recovery rates of factories began to diverge: in the irrigated areas, recovery rates began to fall sharply, while in the non-irrigated regions they continued to increase.

Next, consider location. At the start of the cartel, sugar was produced from beets from the Far West to the Midwest, from California to Michigan. There were forces during the cartel making the Midwest a more attractive location to manufacture beet sugar than the Far West, including California. But the cartel provisions locked production into given locations. We'll show that once the cartel ended in 1974, the Midwest rapidly expanded its share of acres, while the Far West reduced its share (see Figure 12), with California nearly out of the business.

The evidence and analysis below demonstrates convincingly, we think, that the New-Deal sugar manufacturing cartel led to significant distortions in how and where sugar was produced and hence to poor industry performance. ${ }^{5}$ A big reason for the poor performance was the governmentsponsored cartel-provisions. Most legal-cartels likely reach deals that hurt performance. Government provides enforcement powers in legal-cartels, yet usually demands a role in structuring the cartel. In choosing the provisions it wants, there is little reason to think government will place a big weight on "efficient" production as compared to many other potential criteria. Caves and Salant (1995) make this point, that production distortions in legal-cartels should be no surprise (see, e.g., p. 98). Moreover, as we'll argue below, the distortions from government-sponsored provisions may lead to significant losses in producer surplus in a manner reminiscent of arguments by Posner (1975) that the cost of monopoly would be larger than Harberger triangles.

We started the paper by saying not much was known about how cartels influence indus-

\footnotetext{
${ }^{5}$ Other studies of the impact of legal-cartels on industry performance include Roller and Steen (2006) and Symeonidis (2008).
} 
try performance. Demonstrating, as we have, that legal cartels can lead to significant production distortions is important since these cartels have played big roles in economies past and present. Legal-cartels were widespread in the United States during the Great Depression. Cole and Ohanian (2004) argue that cartelization prolonged the Depression. ${ }^{6}$ Today they are common in other countries, like Japan. Porter and Takeuchi (1999) argue that legal-cartels are likely responsible for poor performance in many Japanese industries. According to them (p. 71), "data on the 1,379 registered cartels between 1973 and 1990 showed that cartels were far more prevalent in the failure industries than in the successes," and they attribute this poor performance to the cartels (see also Porter and Sakakibara (2004)).

\section{The New-Deal Sugar Cartel}

In this section, we provide more details about the New-Deal sugar cartel, as well as some other facts about U.S. sugar manufacturing.

There are three major industry segments in U.S. sugar manufacturing. First, beet-sugar manufacturers process beets into white sugar. Second, raw cane-sugar manufacturers process sugarcane plants into raw cane-sugar. This raw sugar is an intermediate good, and is not for consumption. Third, sugar refiners process raw cane-sugar into white sugar. They process raw cane-sugar from domestic producers and foreign producers. ${ }^{7}$

There were attempts to cartelize the U.S. sugar industry before the Great Depression. In fact, these episodes have received extensive study. As with most cartel studies, this literature focuses on the success of the cartels in raising prices (see, e.g., Genesove and Mullin (2001)). These cartels were not legal-cartels, and members were typically concerned that they might be violating the law.

\footnotetext{
${ }^{6}$ If industries wanted to cartelize during the Great Depression, the U.S. government required that the industries agree to greater bargaining power for labor. This is the government-sponsored cartel provision that Cole and Ohanian study.

${ }^{7}$ In terms of industry classification codes, white sugar is made from beets in factories classified by the Census in "Beet Sugar Manufacturing (SIC 2063/NAICS 311313)." Sugarcane is processed into raw cane-sugar in factories classified in "Raw Cane Sugar (SIC 2061/NAICS 311311)." Raw cane-sugar is processed into white sugar in factories in "Cane Sugar Refining (SIC 2062/NAICS 311312)." Again, we focus here on the beet sugar segment of the industry.
} 
During the Depression, the U.S. government changed its view about cartels. Many cartels were started under the auspices of the National Recovery Administration. It was during this time that the New-Deal sugar cartel was formed. Though the U.S. government encouraged the formation of the cartel, there were significant disagreements between the industry and government regarding how the cartel should be structured. ${ }^{8}$ The first plan submitted by the industry consisted solely of provisions to limit sugar sales: quotas on foreign imports and, at home, restrictions on firm entry, along with firm sales quotas (see Heston (1987), p. 99). ${ }^{9}$ The first plan was rejected by the government for not providing enough benefits for beet and cane farmers. The industry agreed to a compromise plan which was passed in the 1934 Jones-Costigan Act (see Heston (1987), pp. 100-117). This act, and later amendments to it, are known as the "Sugar Acts."

The compromise plan included the provisions to limit sugar sales in the first plan plus three new provisions to more directly benefit farmers. First, there was to be no entry of farmers. At the start of the cartel, beet farmers were given an acreage "allotment." They could grow beets on an amount of acres that was no greater than this allotment, with the allotment tied to their beet acreage before the cartel. This allotment could not be sold, though it could be passed down to family members. ${ }^{10}$

Second, there was the tax/subsidy scheme. Subsidies were to be paid to farmers in the beetsugar and raw cane-sugar industries for "voluntarily" agreeing to abide by allotments. To pay for the subsidies, the cartel instituted a tax on (white) sugar production in the United States. Hence, this tax was paid by the sugar refiners and the beet-sugar producers (but not the raw cane-sugar

\footnotetext{
${ }^{8}$ There were, of course, significant disagreements in the industry as well.

${ }^{9}$ Only rarely, like with the fall of Cuba, would the government allow entrants (see below).

${ }^{10}$ One can imagine that in running such an allotment system: (1) many questions would arise about how allotments could be transferred and (2) a large bureaucracy would be needed to administer the system. The system was run at the county level, and significant resources were devoted to it. We were fortunate enough to find a Handbook issued by the USDA to counties with the rules for administering the program (in the Great Western Sugar Collection at the University of Colorado, Boulder). The Handbook is hundreds of pages. Finally, though we said there was no entry of new farmers, there was a mechanism to let a very small number of farmers into the cartel each year. In each county, the number of acres of allotment given to new farmers was no more than 1 percent of existing allotments.
} 
producers who did not produce white sugar). In aggregate, the taxes collected were roughly equal to the subsidies (plus the expenses to administer the program), so the program was revenue neutral. ${ }^{11}$ The tax/subsidy program amounted to a side-payment from the sugar refiners (SIC 2062) to the beet (SIC 2063) and raw cane-sugar (SIC 2061) industries. The sugar refiners paid about half the taxes, yet received no subsidies (since the industry had no farmers). The subsidies received by the beet-sugar and raw cane-sugar industries greatly exceeded the taxes they paid (see below).

While the beet industry clearly received a side-payment from the sugar refiners, were the beet farmers the beneficiaries? Obviously the beet factories had an incentive to change their contracts with farmers to capture some of the subsidies. In order to forestall this, the cartel agreement had a third provision to benefit farmers whereby the government was given a formal role (described below) in the negotiation of contracts for beets and sugarcane. As we show, the government used this influence to ensure that farmers received the lion's share of the subsidies.

As we show below, these three provisions distorted incentives for efficient production, at each factory, and in where the industry was located. The factories agreed to the deal since the government blocked competition. Consider the sugar refiners first. As we mentioned, there were quotas on foreign sugar. But, importantly for the refiners, most of this sugar had to be in raw form, that is, it could not be refined sugar. For example, imports of refined sugar from Cuba were limited to 22 percent of the Cuban sugar quota (see Ballinger (1974), p. 34). This was a big break for the refiners who had experienced increased competition from Cuban refined sugar in the early 1930s. As for beet sugar producers and raw cane sugar producers, they were protected from foreign competition with the quotas, and from domestic competition with the entry restrictions.

The cartel, by limiting competition, was successful in changing the path of U.S. sugar prices. Sugar prices are presented in Figure 1. ${ }^{12}$ Each price series is deflated by the U.S. GDP-deflator (1929

\footnotetext{
${ }^{11}$ The running of the subsidy system was done by the same bureaucratic structure set up to monitor farmer allotments.

${ }^{12}$ Data sources for all figures are given in Appendix A.
} 
dollars). There is a "world" price, which is a raw cane-sugar price (FOB Caribbean). We also plot a U.S. raw cane-sugar price (the price in New York City). Lastly, we plot the average factory-gate price for U.S. beet sugar manufacturers. We have deducted from this price the cartel-tax mentioned above. ${ }^{13}$ Before 1934, the U.S. sugar industry was protected by a tariff, and hence U.S. and world sugar prices moved together. World and U.S. sugar prices fell dramatically in the 1920s. The cartel had two effects on prices. First, U.S. prices were decoupled from world prices. Second, by limiting domestic competition, U.S. sugar prices now grew roughly at the rate of general prices (in the case of the New York raw sugar price) whereas before they had fallen. As part of the cartel agreement, the government promised consumers a "fair" sugar price. In practice, the government interpreted this as meaning that raw sugar prices in New York should roughly grow at the rate of the general level of prices. Hence, the cartel did a reasonable job of hitting this "fair" price target.

Below we'll show that the price of sugar relative to the price of (many of) the industry's major inputs increased significantly during the cartel. There is little doubt that sugar manufacturing was very profitable during the cartel. It's not surprising, then, that when the government decided to allow three new beet factories to open in 1963 (following the fall of Cuba), there were 30 applications submitted (Herder (1964)).

In 1974, world sugar prices soared, and the cartel lost its political support. The Sugar Act was not renewed, and the cartel ceased. Only one provision remained: foreign quotas. In fact, foreign quotas have fallen significantly in the post-1974 period. Still, U.S. sugar prices have fallen since the early 1980s (see Figure 1). The raw sugar price in New York has fallen from four cents to nearly two cents per pound. There are two major reasons for this. First, competition in the domestic sugar industry has increased (as there are no longer entry restrictions, etc.). Second, the industry now faces a significant domestic competitor, that is, producers of high fructose corn syrup

\footnotetext{
${ }^{13}$ The beet sugar price is the U.S. Census of Manufactures price. We cannot calculate unit prices from Census data after 1992 since shipment quantity data are suppressed to maintain confidentiality.
} 
(HFCS).

We now turn to studying the impact of the cartel provisions on how, and where, sugar was produced in the United States during the New-Deal cartel period, 1934-74.

\section{A Model of Sugar Manufacturing}

In this section we develop a simple model of sugar manufacturing, of how a factory and its surrounding farms choose to produce sugar. We then use the model to illustrate the impacts of the cartel-provisions on beet quality and recovery rates. The focus is on a single factory. Later we discuss a model of how regional size is determined.

\section{A. Technology - Farming}

We assume for simplicity that there are only two farm inputs, $L$ and $M$, the units of land or acres devoted to beets and the materials (seed, fertilizer, water, etc.) used for growing beets. ${ }^{14}$ These inputs produce sugarbeets that weigh $T$ tons with sugar content, or quality, $z$.

We suppose tons follows

$$
T=T(L, M)
$$

where $T(L, M)$ is increasing in both arguments and homogeneous of degree one. We assume quality follows

$$
z=z(L, M)
$$

where $z(L, M)$ is increasing in $L$ and decreasing in $M$, and is homogeneous of degree zero.

Our choice of the technologies $T(L, M)$ and $z(L, M)$ is dictated by evidence. There is significant experimental evidence that shows increases in materials per acre leads to greater tonnage of beets per acre but also to lower quality of beets, that is, that $T$ is increasing in $M$, while $z$ is decreasing in $M$. Let's denote the amount of sugar-in-the-crop by $S$, where $S=z T$. Experimental

\footnotetext{
${ }^{14}$ We discuss other inputs below.
} 
evidence shows that $S=z(L, M) T(L, M)$ is increasing in $M$, but only up to a point, and may actually fall if enough $M$ is applied. ${ }^{15}$ But for this paper, we'll assume that $S$ is strictly increasing in $M$ (i.e., $S_{M}>0$, where $S_{M}$ is the partial derivative).

While much of this experimental evidence was developed after 1934, it's clear that the industry had knowledge of the relationship between materials $M$ and beet quality $z(L, M)$ at the time the cartel started. Shortly after the cartel formed, a United States Department of Agriculture (USDA, 1939) study stated that

there are certain cultural practices which have a consistently adverse effect upon the quality of the beet. For example, excessive manuring, which creates a rank top growth, frequently leads to delayed maturity and relatively low sugar content, but high tonnage per acre. Late irrigation has a similar effect. (p. 27)

As the report makes clear, (late) irrigation increases tonnage but reduces quality, as does using excessive manure (i.e., fertilizer).

\section{B. Technology - Factory}

The factory processes the beets from the farm. In addition to the beets, we assume for simplicity that there is only one other factory input, $E$, which we will denote "energy." We assume that the amount of (white) sugar produced, $Y$, follows

$$
Y=\widetilde{F}(E, T, z)=F(E, T) z^{\mu}
$$

where $F(E, T)$ is homogeneous of degree one, and $\mu \geq 1$. This says that if we double tons and energy, keeping sugar content fixed, then we double sugar produced.

\footnotetext{
${ }^{15}$ See, e.g., Hexem and Heady (1978).
} 
The extraction rate for the above technology, that is, the percentage of sugar in the beets that is ultimately extracted as white sugar, or $Y / S$, is

(4) $\quad \frac{Y}{S}=\frac{Y}{z T}=F\left(\frac{E}{T}, 1\right) z^{\mu-1}$

where we have used the fact that $F(E, T)$ is homogeneous of degree 1 . Note that if $\mu>1$, then for a given amount of energy per ton, $E / T$, the higher the percentage of sugar in a beet, the higher the extraction rate. We'll assume $\mu>1$ below, that beets denser in sugar are "easier" to process.

\section{Input and Output Prices}

For input prices, we assume the industry purchases energy (the factory composite) and farm materials at fixed prices, $p_{E}$ and $p_{M}$. Next consider the land input. In the local vicinity of a factory, the amount of land devoted to sugar beets likely influenced land rental rates. We'll assume that the rental rate of land for farmers growing beets, denoted $r(L)$, depended on the amount of land the factory used, in particular, $r^{\prime}(L)>0$.

Before the cartel, the price of sugar, denoted $p_{Y}$, was equal to the world price plus a tariff. Hence, we'll assume the price was taken as given by the industry. ${ }^{16}$

\section{Profit Maximization: Before Cartel}

Typically in this industry the farms and factory were not jointly owned. Rather, the factory would sign contracts with farmers to grow beets. We discuss these contracts below. For now we'll assume that with these contracts, the factory and farmers were able to achieve the joint profit maximizing outcome. There is a long tradition of at least starting with the joint profit maximizing problem. First, it's typically the easiest way. Second, there are good reasons to expect the industry participants to settle on contracts that achieve joint profit maximization.

\footnotetext{
${ }^{16}$ This is, of course, an approximation since transportation costs were a non-negligible part of delivered costs.
} 
The joint profit maximization problem is then

$$
\max _{E \geq 0, L \geq 0, M \geq 0} \pi=p_{Y} F(E, T) z^{\mu}-p_{M} M-r(L) L-p_{E} E .
$$

where the prices are taken as given. Note this problem determines a factory size, but not farm size.

Our simple model, then, of how the factory and farm made sugar before the cartel is summarized in equation (5). We can use this to perform comparative statics, like examining how increases in the price of sugar influenced beet quality. We'll do this in the next section.

\section{Impacts of Cartel on Production: Theory}

In this section we use the model to analyze the impact of some of the cartel's provisions, like those raising price, the subsidy to farmers, and government's role in contracting. In the next section, we'll discuss how much the cartel increased price, how large the subsidies were, and how much the government influenced contracts.

We now modify equation (5) above to study cartel provisions. Since the government was targeting $p_{Y}$ to the general price level during the cartel period (see discussion in Section 2), we'll assume as above, and as an approximation, that the industry took $p_{Y}$ as given during the cartel too. During the cartel period, the factory paid a tax $\tau$ on the amount of (white) sugar $Y$ produced, or $\tau Y$. Farmers received a subsidy $\sigma$ on the amount of sugar $S$ produced on the farm, or $\sigma S$. As shown below, the net payment to the industry was positive and quite large. The total revenue received by the industry equals market sales, less taxes and plus subsidies,

$$
\left(p_{Y}-\tau\right) Y+\sigma S=p_{Y}^{N} Y+\sigma S
$$

where $p_{Y}^{N}=\left(p_{Y}-\tau\right)$ is the net sugar price. The joint profit maximization problem here is

$$
\max _{E \geq 0, L \geq 0, M \geq 0} \pi=\sigma z T+p_{Y}^{N} F(E, T) z^{\mu}-p_{M} M-r(L) L-p_{E} E
$$

where the prices are taken as given. 


\section{A. Provisions Raising the Price of Sugar}

The cartel provisions in the initial plan, like the provision of no firm entry and foreign quotas, led to higher sugar prices. In order to examine the impact of raising sugar prices in equation (6), we'll make some simplifying assumptions. We'll assume $T=T(L, M)$ and $z=z(L, M)$ have the following functional forms: $T=A_{T} M^{\lambda} L^{1-\lambda}$ and $z=A_{z} M^{-\psi} L^{\psi}$, if $A_{z} M^{-\psi} L^{\psi}<\bar{z}$, where $\bar{z}<1$, and $z=\bar{z}$ if $A_{z} M^{-\psi} L^{\psi} \geq \bar{z}$. Regarding $F(E, T)$, the substitutability in production between factory inputs $E$ and tons $T$ is likely not very good. For the proofs in this paper, we'll make the strong assumption that $F()$ is Leontief, that is, $F(E, T)=A_{F} \min \left(a_{E} E, a_{T} T\right)$. But we have also explored the case where $F(E, T)$ is constant elasticity of substitution (CES), that is,

$$
F(E, T)=A_{F}\left[\theta\left(a_{E} E\right)^{\gamma}+(1-\theta)\left(a_{T} T\right)^{\gamma}\right]^{\frac{1}{\gamma}}
$$

In particular, we have explored and will briefly discuss the solutions to the optimization problem when $\gamma \leq 0$, that is, where substitution is Cobb-Douglas or less.

In the case where $F(E, T)$ is Leontief, a necessary condition for profit maximization is that $a_{E} E=a_{T} T$ so that $F(E, T)=A_{F} a_{T} T$. Then the firm's maximization problem is

$$
\max _{L \geq 0, M \geq 0} \pi=\sigma S+p_{Y}^{N} Y-p_{M} M-r(L) L-p_{E} \frac{a_{T}}{a_{E}} T
$$

where $S=z T$ and $Y=A_{F} a_{T} T z^{\mu}$.

Now, we need to make a few parameter assumptions. To ensure that $Y=A_{F} a_{T} T z^{\mu}$ is increasing in $M$, we assume that $\lambda>\mu \psi \cdot{ }^{17}$ To ensure that it's profitable to produce sugar, we assume $p_{E}$ is "small" and $r(0)$ is "small." To ensure an upper bound on factory size, we assume $r^{\prime}(L) \geq \widetilde{r}>0$.

We can now analyze the impact of increasing prices on production, in particular, on $m=$ $M / L$, and hence quality $z$ (which depends on $m$ ).

\footnotetext{
${ }^{17}$ To see this, write $Y_{M}=(Y / M) \epsilon_{Y, M}$ where $\epsilon_{Y, M}$ is the elasticity of $Y$ with respect to $M$, and where $\epsilon_{Y, M}=$ $\epsilon_{T, M}+\mu \epsilon_{z, M}=\lambda-\mu \psi$. Note that since $\mu>1, \lambda-\mu \psi>0$ implies $\lambda-\psi>0$, which implies $S$ is increasing in $M$, since $\epsilon_{S, M}=\epsilon_{T, M}+\epsilon_{z, M}=\lambda-\psi$.
} 
Proposition 1. Suppose $T(),. z($.$) , and F($.$) have the functional forms above, and that the parame-$ ter assumptions hold. Then there is a unique solution to (7), and its interior. Denote it $\left(L^{*}, M^{*}\right)$, with $m^{*}=M^{*} / L^{*}$. For a given subsidy rate $\sigma \geq 0$, increases in $p_{Y}^{N}$ lead to increases in $m^{*}$.

We provide a proof of this in Appendix B. Increases in sugar prices, then, decrease quality. Here is the intuition. When $F(\cdot)$ is Leontief, energy is proportional to tonnage. Then it's as if there is a "tax" at the factory on each ton processed. An increase in the tax will be a force for higher quality. Increases in sugar prices reduce the "real" tax (the price of energy relative to the price of sugar), a force for lower quality. Hence, at the factory, there is a force toward lower quality.

Increases in the price of sugar also decrease "real" material prices, $p_{M} / p_{Y}$. Cheaper materials prices, everything else equal, is a force for lower quality. But "real" land prices (for fixed $L$ ), $r(L) / p_{Y}$, also fall, a force for higher quality. With higher sugar prices, the factory will expand production, and with our assumption that land prices increase with scale $L$, real material prices fall more than real land prices, and hence at the farm there is also a force toward lower quality.

What happens to the extraction rate, $Y / S$ ? Recall the extraction rate given in equation (4), $F(E / T, 1) z^{\mu-1}$. Since $m$ increases, $z^{\mu-1}$ falls (assuming $\mu>1$ ), and hence there is a direct adverse impact on the extraction rate. In the Leontief case, $E / T$ is fixed, so the extraction rate falls. But for the more general $C E S$, with $-\infty<\gamma \leq 0$, since there is an increase in the price of sugar, energy per ton $E / T$ may increase (as extracted sugar is more valuable now). Hence, there are two offsetting effects and the net impact is ambiguous.

In sum, the initial cartel provisions were a force for lower quality, though the impact on the extraction rate is ambiguous. As we'll show, the provisions to benefit farmers were also a force for lower quality, hence compounding the price effects, but also a force for lower extraction rates. 


\section{B. Subsidies to Farmers}

The subsidy to farmers created a distortion, one different from the price distortion. The factory was now being paid for sugar that was not extracted from the beets, namely $z T$. Proposition 2 shows that the subsidy also decreases quality. One expects the subsidy to distort quality more than price increases, and Proposition 3 will show that.

Proposition 2. Suppose $T(),. z($.$) , and F($.$) have the functional forms above, and that the para-$ meter assumptions hold. For a given price $p_{Y}^{N}$, increases in $\sigma$ lead to increases in $m^{*}$.

We provide a proof of this in Appendix B. So, increases in the subsidy also decrease quality. How about the extraction rate? In the Leontief case, $E / T$ is fixed, so the extraction rate falls. How about the $C E S$ case, with $-\infty<\gamma \leq 0$ ? In the case of increasing prices, there was a force for making $E / T$ larger (the force being extracted sugar is more valuable). This force is not present in the case of increasing subsidies (since price has not changed). We can show that for the $C E S$ case the extraction rate falls when subsidies increase. ${ }^{18}$

For the next proposition, we want to compare two government policies, one which raises the price of output a given amount, one which raises the subsidy a given amount, and where both raise industry revenue the same amount. We show quality falls more in the latter policy. Then we have

Proposition 3. For the functional forms above, increases in the subsidy rate decrease quality more than increases in price (for two policies that raise industry revenue the same amount).

We provide a proof of this in Appendix B.

\footnotetext{
${ }^{18}$ When $F()$ is CES with $-\infty<\gamma \leq 0$, we can provide conditions (similar to those above) under which we have a unique solution to the first order conditions. Under these conditions, if subsidies are increased, the extraction rate falls. Showing that the second order conditions are also satisfied is difficult. We can show second order conditions for the Leontief case, and that is why we present proofs for this case.
} 


\section{Government Role in Contracting}

Here we show that government's role in contracting was also a force for lower quality. As mentioned above, farms and factories were not jointly owned. Farmers and factories signed contracts at the start of each season. Among other things, the contracts specified: (1) the number of acres a farmer would plant, say $L=\bar{L}$, and (2) the payment per ton of beet from the factory, which we denote $p_{T}\left(p_{Y}^{N}, z\right)$. The payment per ton often had the form $p_{T}\left(p_{Y}^{N}, z\right)=\theta \cdot z \cdot p_{Y}^{N}$, that is, it was the product of three numbers: a parameter $\theta \epsilon(0,1)$, sugar content $z$ and the net price $p_{Y}^{N}$. The total payment to the farmer would then be $p_{T}\left(p_{Y}^{N}, z\right) T=\theta p_{Y}^{N} z T$. The contract, then, called for the factory to pay farmers for the sugar (in the crop) they produce, $z T$. The marginal return to producing another unit of sugar $z T$ was a fraction $\theta$ of the sugar price $p_{Y}^{N}{ }^{19}$

Consider the farmer's problem given this contract. The farmer would solve

$$
\max _{M \geq 0} \pi_{f a r m}=\theta_{B} p_{Y}^{N} z T-p_{M} M-\bar{r} \bar{L}
$$

where $\bar{r}$ and $\bar{L}$ were taken as given by the farmer, and $\theta_{B}$ is the factory-payment parameter before the cartel. Our assumption has been that, before the cartel, this type of contract, with factorypayment parameter $\theta=\theta_{B}$, was able to achieve the joint profit maximizing outcome (or come very close), and that the optimizing choice for $M$ here, say $\widetilde{M}$, was the same as that for equation (5).

Now, let's consider the farmers' problem during the cartel. Denote the factory-payment parameter during the cartel by $\theta_{D}$, and let $\eta$ denote the share of the subsidy that goes to farmers. The farmers' problem is

$$
\max _{M \geq 0} \pi_{f a r m}=\theta_{D} p_{Y}^{N} z T+\eta \sigma z T-p_{M} M-\bar{r} \bar{L}
$$

\footnotetext{
${ }^{19}$ Since it was the factory's "job" to extract the sugar, basing the farmer's payment from the factory on extracted sugar $Y$ would obviously have led to significant production distortions. That is why the factory payment to the farmer was based on quantities under the farmer's control, like $z$ and $T$. In many contracts, the payment was roughly proportional to the amount of sugar the farmer produced, $z T$. Note that while the subsidy injected into the industry was in a form proportional to $z T$, its impact was to differ markedly from the contract payment. The industry had never before received a payment for $z T$, only $Y$.
} 
Recall the joint profit maximization problem when there was a subsidy, that is, equation (6). We'll assume that we can achieve these profits with the parameters $\theta_{D}=\theta_{B}$ and $\eta=\theta_{B}$. The marginal return to the farmer of producing another unit of sugar $z T$ is then $\theta_{B} p_{Y}^{N}+\theta_{B} \sigma=\theta_{B}\left(p_{Y}^{N}+\sigma\right)$.

As an institutional matter, the subsidy payments $\sigma z T$ were sent to farmers, that is, $\eta=1$.

We can achieve the above marginal return $\theta_{B}\left(p_{Y}^{N}+\sigma\right)$ if we set $\theta_{D}$ in (8) to satisfy

$$
\left(\theta_{D} p_{Y}^{N}+\sigma\right)=\theta_{B}\left(p_{Y}^{N}+\sigma\right)
$$

Let $\theta_{D}^{*}$ denote the solution to the above equation. Rearranging, we have that

$$
\left(\theta_{B}-\theta_{D}^{*}\right) p_{Y}^{N}=\left(1-\theta_{B}\right) \sigma
$$

An immediate implication is that $\theta_{D}^{*}<\theta_{B}$. In words, the farmer should get a smaller share of $p_{Y}^{N}$ given that the farmer receives the entire subsidy. The larger is $\sigma$, the smaller is $\theta_{D}^{*}$.

If $\theta_{D}=\theta_{D}^{*}$, the subsidy, of course, decreases quality. The reduction in quality would be the same reduction that we calculated above in Proposition 2. But if the government is able to pressure factories to choose $\theta_{D}>\theta_{D}^{*}$, this will lead to a greater reduction in quality than would occur under joint profit maximization. We discuss the extent of government pressure below.

\section{Farmer Allotments}

Farmers were given allotments of acres to grow beets. If these allotments were binding (i.e., if farmers wanted to grow beets on more acres than allotted), then this would have an impact on the choice of factory and farm inputs. This could be analyzed by including in equation (6) a restriction that $L \leq \widetilde{L}(\widetilde{L}$ being the allotment). If the constraint was binding, the operation would substitute other inputs, like fertilizer, for land, another force for low quality. ${ }^{20}$

\footnotetext{
${ }^{20}$ Existing factories were given sales quotas $\bar{Y}$ each year. Since population was growing, and since the government tried to keep the price of sugar fairly constant relative to general prices, these sales quotas $\bar{Y}$ grew over time. Hence, factory production was allowed to expand. If these sales quotas were binding, then the operation might make more money by substituting inputs away from making $Y$ to making $S$. For example, by decreasing expenditure on $E$, and increasing expenditure on $M$, the operation would make less $Y$ (beets would be poorer quality and processed "less") and more $S$.
} 


\section{The Cartel's Impact on Prices, Subsidies and Contracts}

The model above illustrated that increases in sugar prices and subsidies will decrease beet quality. In this section, we show that the cartel had a big impact on sugar prices, that subsidies were large (relative to revenues), and that the government was effective in ensuring farmers received the lion's share of the subsidies.

\section{A. Price of Sugar}

In this section we'll argue that the cartel was successful in raising the "real" price of sugar. We do this by (1) showing that the price of sugar rose significantly relative to most of the industry's inputs during the cartel and (2) arguing that if there had been no cartel, the price of sugar would have risen much less than it actually did.

In Figure 2, we plot the price of sugar relative to some of the industry's inputs. We plot $p_{Y, t}^{N} / p_{M, t}$ and $p_{Y, t}^{N} / p_{E, t}$ in the upper left and upper right panels, respectively. ${ }^{21}$ We use fertilizer prices to proxy for materials, and coal prices to proxy for energy prices. These relative price series have similar patterns. The price of sugar is falling relative to each input price before the cartel, then it begins to increase with the cartel. The price of sugar relative to land prices, $p_{Y, t}^{N} / p_{L, t}$, is in the lower left hand panel, and looks like the other two relative prices before and after the start of the cartel. After WWII, the relative price begins to fall, and is below its 1934 price by the late 1950s.

For simplicity, the model above included only two farm inputs and one factory input. On the farm, in addition to materials and land, the major inputs were capital and labor. To discuss farm-capital, we could add a harvesting stage to the model. Assume beets need to be harvested before processing in the factory. We could assume a unit of capital is needed to harvest a ton of beets. There would then be a per ton harvesting cost, or "tax," much as there was a per ton energy cost (when $F($.$) was Leontief as in (7)$ ). Then, if the price of sugar increases relative to the cost of

\footnotetext{
${ }^{21}$ We plot two real sugar prices. The (real) Census of Manufacturers price is the relevant price for beet factories. But we also plot the raw price series as well since the Census price is not available in all years.
} 
capital, the "harvesting" tax falls, leading to greater tonnage, and lower quality. ${ }^{22}$ In Figure 2 (in the lower right hand panel) we plot $p_{Y, t}^{N} / p_{K_{f a r m, t}}$, where $p_{K_{f a r m, t}}$ is the price of farm-capital. The pattern in this panel is the same as in the upper two panels: The price of sugar is falling relative to capital until the start of the cartel, and then it grows, and grows rather dramatically.

In sum, the price received by beet sugar factories rose relative to the price of many of the industry's inputs. This leads us to the second part: What would have happened to $p_{Y, t}^{N}$ without the cartel? If the counterfactual for the no-cartel case is free trade, then an estimate of U.S. raw sugar prices would be the world price in Figure 1. Sugar prices would have grown much more slowly, and hence $p_{Y, t}^{N} / p_{M, t}, p_{Y, t}^{N} / p_{E, t}, p_{Y, t}^{N} / p_{L, t}$ and $p_{Y, t}^{N} / p_{K, t}$ would have grown much more slowly (and likely would have continued to fall).

Another counterfactual is one where domestic competition was allowed (but foreign import quotas remained). If there had been domestic competition, sugar prices would not have grown as fast as they did. Why? The economic logic is clear. Since the price of sugar relative to its inputs was going up, economic profits were growing. These large profits would have led to entry of new firms, or more intense competition among existing producers. Prices would have not increased as fast. This can be seen since the cartel's demise in 1974. When restrictions on domestic competition were lifted, the price of sugar relative to general prices has fallen (see Figure 1). Domestic competition among sugar producers, and HFCS producers, has led to these price declines. These declines have occurred even as foreign quotas have been cut back dramatically, from 7 to roughly 1.3 million tons. ${ }^{23}$

\section{B. Subsidies with Cartel}

Here we show that subsidies were big relative to industry revenues. The rate of subsidy to farmers equaled $\phi_{t}$ cents per 100 pounds of commercially recoverable sugar. The commercially

\footnotetext{
${ }^{22}$ We'll discuss farm-labor below.

${ }^{23}$ A quota of 7 million tons was established in late 1974. (see Ballinger (1974)). As a result of the Uruguay Round of GATT, the annual total quota cannot be less than 1.256 million short tons. Recent quotas have been close to minimum. For example, the 2005 quota was 1.3 million short tons (see Haley and Ali (July 2007)).
} 
recoverable sugar in a tons of beets was defined to be $(2000) \cdot(\bar{x} z T)$ pounds, where $\bar{x}$ was an historical rate of extraction. ${ }^{24}$ The extraction rate $\bar{x}$ in the cartel's formula was based on the extraction rate of the region in which the factory was located (so, it was not tied to the factory's extraction rate), and was an average of past (regional) extraction rates.

In equation (7), then, we have that $\sigma_{t}=\phi_{t} \bar{x}$. From 1934 until 1941, $\phi_{t}=60$. From 1942 until 1974, $\phi_{t}=80$. The rate of tax equaled 50 cents per 100 pounds of (white) sugar, that is, $\tau_{t}=50$, for the duration of the cartel. Hence, from 1934 until 1941, the subsidy rate $\sigma_{t}$ was about 20 percent higher than the tax rate $\tau_{t}$ (i.e., 60/50), and from 1942 until 1974, the subsidy rate was about 60 percent higher (i.e., 80/50).

In Figure 3, we plot the total subsidies received by the industry relative to revenues, that is, $\sigma_{t} S_{t} / p_{Y, t}^{N} Y_{t}{ }^{25}$ The subsidies were quite big relative to revenues at the start of the cartel, roughly 20 percent of revenue. The subsidies were in nominal terms and hence over time they fell relative to sugar prices. Still, they remained above 10 percent of revenues into the mid 1960s.

\section{Contracts During the Cartel}

During the cartel, the government became involved in contract negotiations. The government had direct control over contracts when factories grew sugar crops. ${ }^{26}$ Only a small minority of beet factories grew beets, but the USDA influenced beet contracts in other ways. ${ }^{27}$ The Jones-Costigan Act (again, the Sugar Act) empowered the USDA to hold hearings and issue reports on contracts. The USDA was also to serve as a mediator when growers and processors could not agree on a contract. The USDA was involved in negotiating many beet contracts, including a number of the

\footnotetext{
${ }^{24}$ For example, the commercially recoverable sugar in a ton of beets that were 10 percent sugar, and assuming an extraction rate of 95 percent, was $(2000) \cdot(.95)(.10)=190$ pounds.

${ }^{25}$ Note that

$$
\frac{\sigma_{t} S_{t}}{p_{Y, t}^{N} Y_{t}}=\frac{\sigma_{t}}{p_{Y, t}^{N}} \frac{S_{t}}{Y_{t}}=\frac{\sigma_{t}}{p_{Y, t}^{N}} \frac{1}{x}=\frac{\bar{x}}{x} \frac{\phi_{t}}{p_{Y, t}^{N}}
$$

where $x$ is the actual extraction rate. $\phi_{t} / p_{Y, t}^{N}$ is typically a percentage point or two below $\sigma_{t} S_{t} / p_{Y, t}^{N} Y_{t}$.

${ }^{26}$ See Section 301(4) of the 1937 Sugar Act.

${ }^{27}$ By contrast, many sugarcane factories were involved in growing cane.
} 
1967 contracts (Federal Register, v. 32 n. 7, January 12, 1967, pp. 312-316). In fact, the USDA would sometimes write contracts. For example, in 1935 Holly Sugar and Great Western Sugar (two large beet sugar companies; see below) could not come to terms with their growers, and in the end, the USDA wrote the contract (USDA, 1939).

The government was widely thought to favor farmers in negotiations. After all, the first cartel plan was rejected because the government believed it did not benefit farmers enough. Recall above where we argued that joint profit maximization implied that the factory-payment parameter $\theta$ should have fallen during the cartel, that is, $\theta_{D}^{*}<\theta_{B}$. We have examined the contracts over time for a large number of factories, and we find that the parameter $\theta$ changed very little during the early cartel years. That is, $\theta_{D} \approx \theta_{B}$. Hence, the government was successful in keeping $\theta$ from falling. Farmers, then, captured nearly all the subsidy going to the beet industry. This meant that the incentives for farmers to expand materials (and reduce quality) were likely much greater than incentives in equation (6).

\section{Beet Quality and Recovery Rates: A "Natural" Experiment}

The cartel, by raising price, by subsidizing sugar-in-the-crop, and by interfering in contract negotiations, should have led to lower crop quality, lower extraction rates, and lower recovery rates. We first show that these were indeed the patterns in industry level statistics. Because of the "natural" experiment run in this industry (described below), beet quality and recovery rates should have fallen more in some regions. We then show this was true as well.

\section{A. National Beet Quality, Extraction and Recovery Rates}

We plot the recovery rate at the industry level in Figure 4. The U.S. recovery rate was increasing before the cartel period, reaching about 310 pounds of sugar per ton of beets in 1934. It fell fairly continuously throughout the cartel period, reaching a low of about 240 pounds by the end of the period. It has grown robustly since the cartel ended. In Figure 5, we plot the U.S. average 
sugar content of beets and the average U.S. extraction rate. We set both statistics equal to one in 1934. Both statistics were increasing before the cartel, and both fell during the cartel. ${ }^{28}$ Both statistics have grown since the cartel ended, though the extraction rate has been volatile, and not climbed as much.

As we show below, in the post-cartel period a large part of the industry moved from the West to the Midwest. Historically (i.e., before the cartel), the factories in the West had significantly higher quality and extraction rates, due to weather and soil differences. ${ }^{29}$ So, the post-cartel performance of increasing sugar content and increasing extraction is more impressive once one understands the industry was moving to areas with historically lower quality and extraction rates.

\section{B. Natural Experiment: Irrigated versus Non-Irrigated Regions}

Fortunately for us, there was something akin to a natural experiment run in the industry. While the cartel provisions applied to the whole country, it should have had a much bigger impact on beet quality and recovery rates in some regions as compared to others. In some areas, farmers were able to manipulate beet quality to a much greater extent than other areas.

There were two features of an area that determined how well a farmer could manipulate quality: whether the area had access to irrigated water, and whether the area had predictable rainfall. By irrigating late in a season, a farmer can increase tonnage per acre $T / L$, and sugar per acre $S / L$, though quality $z$ will fall. To do this, to know how late in a season to irrigate to achieve this result, was an important skill. If a farmer literally irrigated an acre the day before harvest, then the beets would simply fill up with water and no sugar would be produced. Tonnage would increase, but sugar per acre would not increase (and quality would crash). Hence, this leads us to

\footnotetext{
${ }^{28}$ These statistics are so volatile because beet quality (and hence extraction) can be significantly influenced by weather, in particular, by rainfall (as described below).

${ }^{29}$ Below, we show evidence that California's beet quality was significantly higher than the national average. Extraction rates were also higher in the West before the cartel. In 1929, the extraction rate was 93 percent in California and Colorado and 87 percent in Michigan (extraction rates are from the 1933 Statistical Abstract of the United States, Table 603).
} 
the second feature: predictable rainfall. If an area was arid, with little rainfall, then this was ideal for being able to manipulate quality (if it had access to irrigated water). If rainfall occurs near a harvest date, it can cause havoc with beet quality. In many areas, farmers are given a date at which to deliver their beets to the factory so as to optimize factory utilization. Hence, there may be no way for a farmer to avoid the consequences of rain.

Before the cartel, these regional differences in ability to manipulate quality were reflected in the types of contracts in each region. In the Midwest, without irrigation, contracts did not call for testing a farmer's beets for their quality. In particular, the payment per ton in non-irrigated regions was $p_{T}\left(p_{Y}^{N}, \bar{z}\right)$, where $\bar{z}$ was the average quality of beets across all farmers. By contrast, in irrigated areas, farmers were assumed to have more control over quality and tonnage, and hence contracts called for testing each farmer's beets. Payments per ton were $p_{T}\left(p_{Y}^{N}, z_{i}\right)$, where $z_{i}$ was the sugar content of farmer $i^{\prime} s$ beets. ${ }^{30}$

So, as the cartel started, we expect to see changes in quality and extraction rates in irrigated areas (particularly, arid areas) as opposed to non-irrigated areas. In the next four subsections, we'll show that this was the case.

\section{Regional Beet Quality}

Many regions in California where beets were grown had ideal conditions to grow and manipulate beets, being arid and irrigated areas. Hence, we begin by comparing the sugar content of beets in California with the national average. Figure 6 shows that before the cartel, the sugar content of beets was significantly higher in California than the rest of the country. During the cartel, the sugar content of Californian beets fell much more than the national average. By the middle to late 1950s, beet quality in California was below the national average.

What is not so clear from Figure 6 (since we are missing some early cartel years) is that

\footnotetext{
${ }^{30}$ See, for example, Koenig (1996).
} 
Californian beet quality started falling very soon after the cartel was established. Figure 7 plots the sugar content of beets for two California factories, Oxnard and Spreckels \#1. ${ }^{31}$ These are the only two factories in California for which we have quality data before and during the cartel. These were large factories and their combined output represented $58 \%$ of California output and $9 \%$ of U.S. output over the period 1930-1934 (average). As seen in the figure, quality begins falling in both factories at the start of the cartel.

\section{Recovery Rates: By Major Company}

Since the major sugar companies were typically located in narrow regions, we can further explore how the cartel influenced regions by examining company level statistics. Since quality data are less readily available than recovery rate data, we'll discuss recovery rates for companies.

There were seven major beet-sugar companies at the start of the Sugar Act: Amalgamated, American Crystal, Great Western Sugar, Holly Sugar, Michigan Sugar, Utah \& Idaho Sugar, and Spreckels. Together these companies produced the vast majority of U.S. beet-sugar output. In Figures $8 \mathrm{~A}-8 \mathrm{~B}$, we display the recovery rates for each of these companies. Again, these companies were typically located in a single region. American Crystal had the widest geographic distribution of factories. Since we have factory level data for the company, we can break the company into two parts - factories in the west and those in the Red River Valley (in Minnesota and North Dakota).

Figure 8A presents recovery rates for American Crystal - West (California and Montana), Spreckels (California), Utah \& Idaho Sugar, and Amalgamated Sugar (Utah and Idaho). ${ }^{32}$ These companies are located in regions with irrigated farming. The recovery rates all share a similar pattern as the U.S. average: a rising recovery rate until 1934, then a fairly quick and steady decline once the cartel begins. American Crystal closed its western factories in the mid 1970's, so that is

\footnotetext{
${ }^{31}$ Following the conventions of the industry, we (often) name factories by the towns in which they are located. Oxnard was located in Oxnard, CA, and Spreckels \#1 in Spreckels, CA.

${ }^{32}$ For Spreckel's Sugar, we only have the total company data for 1937-53 (plotted as the solid line). We have data on its largest factory, Factory \#1, located in Spreckels, CA, for a much longer period (plotted as the dashed-line). It was a huge factory - many times bigger than any other U.S. factory. It amounted to roughly half of Spreckel's production.
} 
why data for them cease. Spreckels Factory \#1 closed in 1982. Utah \& Idaho was closed in the late 1970's, and our data for it end in the mid 1970s. These closures reflect that the industry was moving to the Midwest (see below). Amalgamated Sugar is still an ongoing company, and its recovery rate has increased significantly since the cartel ended.

Note that the level of recovery rates in Figure 8A varied significantly at the start of the cartel. For Spreckels (in California) and American Crystal (West) (mostly in California) recovery rates were as high as 375 pounds per ton of beets in some years. In the other two companies, located in the mountain states, recovery rates never got much above 325 pounds.

Figure $8 \mathrm{~B}$ shows the recovery rate for the other four companies. The Great Western was the largest producer at the start of the cartel, with production primarily in Colorado. For Holly Sugar, we only have one factory - Sydney, Montana. Both of these companies were in irrigated regions. The patterns for these two companies are similar to the U.S. national average. The final two companies are American Crystal (Red River Valley) and Michigan Sugar. Both companies were located in areas with no irrigation. Their recovery rates are somewhat different than the other six companies in that there was no sustained downward fall in recovery rates until the mid 1950's. As we said, when the cartel started, farmers in these regions had much less control over beet quality than farmers in the West. As the cartel progressed, farmers in the Midwest did become more skillful at controlling quality, as we discuss below.

Note that for Michigan Sugar our data for recovery rates end in 1969, though we have one more year in 2002. We have plotted a dashed-line between these two years in Figure 8B. We are quite sure that the trend in Michigan Sugar's recovery rate is similar to the dashed-line in Figure $8 \mathrm{~B}$ since we have the recovery rate for the state of Michigan and it looks very much like this (and Michigan Sugar accounts for a large part of the state's production). Also note in Figure 8B that the recovery rates of the Midwest companies are lower than the mountain-state companies, rarely getting above 300 pounds and typically much lower. Notice also that the volatility of recovery rates 
(of companies) in Figure 8B is greater than that (of companies) in Figure 8A. Companies in Figure $8 \mathrm{~B}$ are most susceptible to late rainfall.

\section{E. Recovery Rates: By Factory}

For many of the companies above, we have data at the factory level. Hence, we can look at an even narrower level of aggregation. We find the same patterns in the factories as in the company data: after the cartel is established, recovery rates begin falling very soon in western factories, but only after some delay in midwestern factories. We present some of the factories in Figures 9A-9B (with the companies that own the factories in parentheses).

\section{F. Recovery Rate Regressions}

Here we run some simple regressions to summarize the company and factory data above. We want to show two things. First, the trend in recovery rates changed when the cartel was established. Second, the change in trend, at the start of the cartel, was much bigger in the West than the Midwest, as farmers in the West had much more control over quality at the start of the cartel.

Let $r_{i t}$ denote the recovery rate for $i$ (in pounds of sugar) where $i$ may be a factory or a company, at time $t$. We assume the recovery rates have the form

$$
r_{i t}=\lambda_{i}+\gamma \cdot t+\varepsilon_{i t}
$$

where each factory has a fixed effect $\lambda_{i}$ (i.e., its own average recovery rate) and there is a common trend $\gamma$ across factories. Since we are trying to establish if the trend changed with the cartel, we will modify this equation to allow for two trends, that is, we estimate the following equation

$$
r_{i t}=\sum_{\tau=1,2} I_{\tau} \cdot\left[\lambda_{\tau, i}+\gamma_{\tau} \cdot t\right]+\varepsilon_{i t}
$$

where $I_{1}=1$ for years $t=1901-33$ (zero otherwise), and $I_{2}=1$ for years $t=1934-50$ (zero otherwise), and where $\lambda_{\tau, i}$ is a fixed effect for $i$ in period $\tau$. We take the second period to be the cartel's first 15 years (when farmers in the West had much greater ability to influence quality than 
those in the Midwest).

We estimate equation (9) on the complete sample of factories, and then on subsets of factories. ${ }^{33}$ Table 1 presents statistics from the regression. Table 2 displays the estimated $\gamma_{\tau}$ coefficients from the Table 1 regressions. In Table 1, there are eight regressions (one for each row). The first regression is for all the factories combined, and for the first period, 1901-33 (labeled "Before"). The coefficient on the trend, $\gamma$, is 1.831, so all factories together gain an average of 1.831 pounds of sugar per year (per ton of beets). The second regression is for all the factories, and for the period 1934-1950 (labeled "During"), and so on.

Table 2 displays the estimated $\gamma^{\prime} s$. Again, it shows that in period 1, before the cartel, all factories together gain an average of 1.831 pounds of sugar per year (per ton of beets). In the second period, in the first 15 years of the cartel, the factories lose 1.357 pounds of sugar per year (per ton). The trend falls about 3.2 pounds per year. The difference in trends is significant at the $0.1 \%$ level. ${ }^{34}$

Consider next the regressions within the West (that is, using only western factories). In the early time period, the factories in the West gain, on average, 2.336 pounds of white sugar per ton of beets. In the second period, the factories lose 2.943 pounds. The trend falls about 5.3 pounds per year with the cartel. The difference in trend is significant at the $0.1 \%$ level. ${ }^{35}$

In the Midwest, the gain was 2.877 pounds per year in the first period. In the second period, the factories gain 0.765 pounds per year. The trend falls about 2.112 pounds per year with the cartel. The difference in trend is significant at the $0.1 \%$ level.

So, the cartel changed the trend in both the Midwest and the West. We next ask if the cartel changed the trend more in the West. In the West, the trend fell about 5.3 pounds per year, and in the Midwest, about 2.1 pounds per year, so the fall in the West is about 3.2 pounds more per year.

\footnotetext{
${ }^{33}$ The list of factories in each regression is given in Table 1.

${ }^{34}$ We use a simple T-test to test the significance of the trend differences.

${ }^{35}$ In California, the gain was 0.975 pounds per year in the first period. In the second period, there was a loss of about 4.485 pounds per year. The difference in trends is significant at the $0.1 \%$ level.
} 
This difference between the West and Midwest of 3.2 pounds is significant at the $0.1 \%$ level. ${ }^{36}$

In summary, then, the regressions confirm what was seen in the figures: with the cartel, there was a change in the trend in factory recovery rates, and the change was greater in the western factories than in the midwestern factories.

\section{Why Recovery Rates Fell for 40 Years}

Why did U.S. average beet quality and U.S. recovery rates keep falling for 40 years? There are a few reasons, some of which have been suggested above. First, in some areas (like California) the biggest fall in the statistics was, in fact, immediately after the cartel was established (as seen above, e.g., Figure 7). But in some regions (like the Midwest), the industry was able to exploit the cartel provisions only after some period. For example, fertilizer works in a similar fashion to irrigation. Through late applications of nitrogen a farmer may be able to increase sugar per acre, though quality will fall (Lord 1994). But, of course, to use fertilizer to manipulate quality without an easy water source like irrigation requires skill and experience that only came through time. ${ }^{37}$ So, the statistics kept falling as "new" areas began to reduce quality.

Second, over time, farmers in all areas became better at manipulating beet quality. ${ }^{38}$

Third, recall the cartel agreement shifted many of the cartel benefits from factories to farmers. But government interference in contracting meant the share of benefits going to farmers grew over time. In particular, factory owners' share of industry revenues (net of government subsidy payments) shrank. The factory share of industry revenues was

$$
\frac{p_{Y}^{N} Y-\theta p_{Y}^{N} z T}{p_{Y}^{N} Y}=1-\theta\left(\frac{Y}{S}\right)^{-1}
$$

where $\theta$ is the factory-payment parameter. Since government interference meant $\theta$ was not changing

\footnotetext{
${ }^{36}$ We test whether this difference of 3.2 pounds is significant with techniques similar to T-tests used above.

${ }^{37}$ In the archival records of companies with factories in non-irrigated areas, like American Crystal, one finds that starting in the early 1960s, company field representatives complain about farmers applying fertilizers too late in the season, thus reducing beet quality.

${ }^{38}$ Farmer experimentation and formal university research improved knowledge of the effects of cultural practices. Improvements in commercial fertilizer gave growers more precise control of nitrogen applications compared to manure.
} 
much, and since the extraction rate $Y / S$ fell throughout the cartel period, the factory share of industry revenue fell. It went from 53 percent in 1935 to 35 percent in 1973 (Table 10, USDA, Sugar Statistics and Related Data, 1974). This shift of revenues to farmers likely meant the incentives of factory owners to maintain equipment fell. Farmers certainly complained that factories were not maintaining their equipment. In the face of these developments, one might expect farmers to purchase the factories. ${ }^{39}$ In fact, there was a significant movement to farmer cooperatives that started in the late 1960s. American Crystal was purchased by farmers in the early 1970s (before the cartel ended). Discussions to make the Great Western a farmer's cooperative started in the late 1960s. When a new factory was allowed to open in 1972, in Renville, MN, it was a farmer's cooperative.

Fourth, while the biggest level of subsidy (relative to revenues) was at the start of the cartel, the price of sugar relative to inputs increased throughout the cartel. So, the price effect would have grown through time.

\section{Beet Quality and Recovery Rates: Other Factors?}

In this section, we discuss other possible explanations for the patterns in the factory and industry statistics presented above.

In analyzing the impact of the cartel, we assumed that the technologies were fixed during the cartel period. But the cartel likely had a negative impact on the rate of technological progress in the industry, so some of the decline in performance is likely tied to this. In particular, the cartel certainly reduced domestic competition, and there is now strong evidence that reduced competition reduces technological progress and productivity. ${ }^{40}$

During the cartel period, there was a major substitution of farm capital for farm labor. When

\footnotetext{
${ }^{39}$ The advantage of moving to a farmer's cooperative was the possibility that the industry could eliminate the distortions brought about by government playing a role in contracting. If a cooperative could eliminate this distortion, then the industry could move to the solutions given by equation (6), that is, the joint profit maximization problem.

${ }^{40}$ For some evidence, see, for example, Bloom et al. (2008), Syverson (2004) and Schmitz (2005).
} 
the cartel started in 1934, growing beets was an extremely labor intensive operation. Weeding and harvesting of beets was costly, and mostly done by labor. Labor costs were a large share of total farm costs. ${ }^{41}$ After WWII, there were significant developments in capital that allowed the industry to substitute significantly from farm-labor to farm-capital. ${ }^{42}$ The substitution of machines for handlabor in harvesting certainly led to lower harvesting costs. And, everything else equal, this was a force for lower quality (as discussed in Section 5 above). But this force likely had limited impact on quality and recovery rates. First, machine harvesting of beets was not introduced in a significant way until the early to mid 1950s. ${ }^{43}$ By this time, the cartel had already had its biggest impact in many areas. In California, much of the fall in beet quality occurred before the early 1950s (see Figure 7). Second, machine harvesting was being introduced in Europe as well, and there is no evidence of declining recovery rates in Europe after WWII (Bridgman, Schmitz and Qi (2007)).

During the cartel period, there were also significant advances in production of fertilizers. Fertilizer became cheap relative to many inputs, in particular, land. In Figure 10, we plot the price of fertilizer relative to land for the United States, California, North Dakota and Minnesota. We see that this relative price did decrease significantly over the cartel period. However, we think this relative price decline was not a major factor in falling quality and recovery rates. First, the relative price of fertilizer did not begin to fall until the mid 1940s. (The price of fertilizer relative to land in California had not fallen to its mid-1920s level until the mid 1940s.) By this time, California had operated for 10 years under the cartel, and quality and recovery rates had fallen significantly already. Second, as above, there were major improvements in fertilizers in Europe, yet recovery rates there did not fall. Third, this relative price kept falling after the cartel, yet quality started

\footnotetext{
${ }^{41}$ Farm-labor costs amounted to (a huge) 46 percent of total farm costs. This evidence is from United States Tariff Commission, Costs of Producing Sugar Beets, 1921, 1922, and 1923. For the years 1921-23, the average cost of producing sugar beets (per acre) was $\$ 85.98$ (which included capital and land costs). The labor cost was $\$ 40.39$, or about 46 percent $(\$ 40.39 / \$ 85.98)$.

${ }^{42}$ The share of farm-labor in total farm costs fell to about 15 percent by the end of the cartel (see Hoff (1984)). This 15 percent figure is for 1982 and includes an imputed value for the owner/farmer's time.

${ }^{43}$ Mechanical harvesters were not commercially available until 1943 and were only adopted widely in the early 1950 s (see, e.g., Timoshenko and Swerling (1957), p. 102).
} 
to increase and has grown significantly. In Figure 10, the relative price of fertilizer in California is 0.2 in the early $1970 \mathrm{~s}$, and is 0.1 in the late $1990 \mathrm{~s}$, so the price fell by half over the period. Similar large reductions are seen in Minnesota.

\section{Location: Theory and Evidence}

Recall the cartel forbade the entry of new farmers. This had the effect of locking the production of sugar into the locations observed at the start of the cartel. Hence, if during the cartel period there were forces making some areas more attractive to produce sugar, the cartel provisions would have led to another distortion: it would have distorted the location of industry. We'll argue there were forces making the Midwest a more attractive location to manufacture beet sugar than the Far West, including California. We'll make our argument concrete in a simple model, where if one region's costs (like North Dakota) grow more slowly than another's costs (like California), then the first region should grow relative to the second. Then we'll turn to evidence.

\section{A. Very Simple Model}

Here we consider the simplest possible (one-period) model of regional size. Consider an entrepreneur deciding to enter sugar production. We will suppress much of the details about sugar production that we considered above. Let the production function for sugar be

$$
Y=G\left(M, L, K_{\text {farm }}, E, K_{\text {fact }}, \ldots\right)
$$

where $K_{\text {fact }}$ is factory-capital, and so on. Let's make the strong assumption that $G()$ is Leontief. Moreover, let's assume the operation can be run at only one scale, say $\bar{Y}{ }^{44}$

Let $c_{\bar{Y}, j}$ denote the unit cost of producing $\bar{Y}$ in region $j$. We assume the same inputs are used across regions, but the costs of the inputs may differ. Some inputs may cost the same, like capital, since it is easily traded. But other inputs will not be traded, like land and labor.

\footnotetext{
${ }^{44}$ That is, we assume span-of-control limits size of the operation.
} 
The profits of an entrepreneur in region $j$ are then

$$
\pi_{j}=\left(p_{Y}-c_{\bar{Y}, j}\right) \bar{Y}
$$

where $p_{Y}$ is the U.S. sugar price. To determine regional size, that is, how many entrepreneurs enter the industry, we assume there is a potential supply of entrepreneurs to this industry in each region. We assume all entrepreneurs have the same skill, that is, earn $\pi_{j}$. However, entrepreneurs have different outside options. As we increase the number of entrepreneurs in the industry in a region, we increase what they must be paid to enter. Let $w_{j}(N)$ denote the outside option (wage) of the Nth entrepreneur in region $j$. We "rank" entrepreneurs so that higher $N^{\prime} s$ have higher outside options, that is, $w_{j}^{\prime}(N)>0$. If $\pi_{j}>w_{j}(0)$, then production occurs in the region, and equilibrium "size" $N_{j}^{*}$ is calculated from

$$
w_{j}\left(N_{j}^{*}\right)=\pi_{j} .
$$

So far, we have discussed a very simple one-period model of regional size. Now, let's introduce time, again in the simplest possible way. Suppose $w_{j}(N)$ does not change with time. Then the industry expands, or contracts, depending on how $\pi_{j}$ changes over time. If price $p_{Y}$ grows faster than regional costs $c_{\bar{Y}, j}$, then the region expands.

Consider the relative size of regions. Let's again make some simplifying assumptions. Suppose the wage function has the same shape across regions, and is given by $w(N)=N^{\chi}$, where $\chi>1$. The relative sizes of two regions, say $N_{1} / N_{2}$, then depends on the ratio

$$
d=\frac{\left(p_{Y}-c_{\bar{Y}, 1}\right)}{\left(p_{Y}-c_{\bar{Y}, 2}\right)}=\frac{1-c_{1}}{1-c_{2}}
$$

where $c_{j}=c_{\bar{Y}, j} / p_{Y}$. We can write $\ln (d)=\ln \left(1-c_{1}\right)-\ln \left(1-c_{2}\right)$. If we consider $c_{j}$ to be a function of time, then

$$
\frac{d^{\prime}}{d}=\frac{c_{2}^{\prime}}{1-c_{2}}-\frac{c_{1}^{\prime}}{1-c_{1}}
$$


where the derivatives are with respect to time. If the two regions have similar initial $\operatorname{costs}\left(c_{1} \simeq c_{2}\right)$, then its easy to show that

$$
\operatorname{sgn}\left(d^{\prime}\right)=\operatorname{sgn}\left(c_{2}^{\prime}-c_{1}^{\prime}\right)=\operatorname{sgn}\left(c_{\bar{Y}, 2}^{\prime}-c_{\bar{Y}, 1}^{\prime}\right),
$$

where $c_{\bar{Y}, j}^{\prime}$ is the derivative of regional costs with respect to time. This simply says that $d^{\prime}>0$, that is, region 1 grows relative to region 2, if region 1's costs grow slower than region 2's costs.

\section{B. Applying the Model to Cartel}

During the cartel period, as we'll show, California's costs of producing sugar grew relative to those in midwestern states. Hence, in the absence of the cartel, the Midwest (region 1 in the model) would have grown relative to California (region 2 in the model). But the industry was not allowed to move, a distortion to efficient production. When the cartel ended, and the restrictions on farmer entry were lifted, we'll show that the Midwest grew relative to the West.

Many inputs to sugar production are traded, like fertilizer and capital, and likely have similar prices across regions. But some important inputs are not traded, like land and labor, and their prices differ a lot across regions. During the cartel period, the price of many inputs used to make sugar increased faster in the West, in particular, California, than they did in the Midwest, in places like Minnesota and North Dakota. Prices on farm labor are easy to obtain, and hourly farm wages in sugar beet farming increased in California relative to that in Minnesota and North Dakota by over 20 percent over the cartel period.

Land prices in California also increased relative to these Midwest states. In Figure 11, we plot the price of farmland in California relative to that in Minnesota and North Dakota. Over the course of the 20th century, the price of California farmland increased significantly relative to North Dakota and Minnesota farmland. There was a huge surge in Midwest land prices in the late 1960s and early 1970s, but the overall trend of increasing relative land price in California is clear.

The increase in California costs relative to Midwest costs implies that California and western 
sugar production should have been shrinking relative to the Midwest during the cartel. Again, the cartel prohibited this adjustment. ${ }^{45}$ But once the cartel ended, the theory predicts that California should shrink sharply relative to the Midwest. In Figure 12, we plot the share of acres devoted to growing sugarbeets in four regions in the United States. Since the cartel ended in 1974, the share of acres in the Midwest has grown significantly, while that in the Far West has shrunk.

\section{Discussion}

We have demonstrated large swings in beet quality, extraction rates, and hence recovery rates following the creation and dissolution of the New-Deal sugar cartel. We have also shown large swings in the industry's location. We have presented evidence that the swings were likely due in large part to production distortions set up in the creation of the legal-cartel. We conclude by discussing two issues. First, we'll argue that the swings in, for example, recovery rates, may well have reflected significant welfare losses to society. Second, if this is true, we ask: How could such a distortionary system have been established? And why wasn't it amended?

We'll begin by arguing that as a matter of theory, the welfare losses could have been big. Consider the provisions raising price, like the quotas on foreign imports. In the usual analysis, price increases reduce consumer surplus and increase producer surplus. Some welfare loss follows because of "Harberger triangles," though the loss is typically small. But here the additional cartel provisions may well have destroyed much of the increase in producer surplus.

Consider the subsidies. The sugar refining industry (again, SIC 2062) sent a subsidy to the beet sugar industry (again, SIC 2062) each year during the cartel. The sugar refiners went along with the program since foreign refined sugar was (largely) prohibited from entering the United States. Consider the impact of the subsidy in the beet sugar industry. Again, the subsidy was not sent lump-sum but was tied to production of sugar on the farm. This led to a production distortion that

\footnotetext{
${ }^{45}$ Of course, the West could have gotten out of sugar production altogether, that is, shrank in absolute terms, but the cartel kept the price of sugar increasing faster than western costs.
} 
reduced profits from operations. As a matter of theory, an industry would take a dollar in subsidy even if it created production distortions that reduced profits 99 cents. That is, it would take a dollar in subsidy even if it "destroyed" 99 cents in producer surplus.

To make matters concrete, consider equation (6) above. Let $v^{*}\left(p_{Y}, \sigma\right)$ denote the maximum profit achieved in equation (6) net of the subsidy. That is, the total maximum return is $v^{*}\left(p_{Y}, \sigma\right)+$ $\sigma S^{*}$, where $S^{*}$ is the total sugar in the crop produced given the optimal choices. Let $v^{*}\left(p_{Y}, 0\right)$ denote the maximum profit achieved in (6) when the subsidy is zero, that is, $\sigma=0$. Then the factory will take the subsidy as long as $v^{*}\left(p_{Y}, \sigma\right)+\sigma S^{*} \geq v^{*}\left(p_{Y}, 0\right)$, or $\sigma S^{*} \geq v^{*}\left(p_{Y}, 0\right)-v^{*}\left(p_{Y}, \sigma\right)$, that is, as long as the subsidy is larger than the loss in profits from the distortion. ${ }^{46}$ So, again, the loss in producer surplus from the subsidy, $v^{*}\left(p_{Y}, 0\right)-v^{*}\left(p_{Y}, \sigma\right)$, can be as large as the subsidy (really, a penny less). This is the sense in which a significant share of producer surplus may have been destroyed.

The cartel actually did two things for beet producers: it raised the price of sugar, from say $p_{Y}$ to $\bar{p}_{Y}$, and gave the industry a subsidy. The loss in producer surplus from the subsidy in this case is $v^{*}\left(\bar{p}_{Y}, 0\right)-v^{*}\left(p_{Y}, \sigma\right)$. To derive an upper bound on the loss in this case, note that the factory is willing to go along with the cartel "package" if

$$
v^{*}\left(\bar{p}_{Y}, \sigma\right)+\sigma S^{*}\left(\bar{p}_{Y}, \sigma\right) \geq v^{*}\left(p_{Y}, 0\right)
$$

where $S^{*}\left(\bar{p}_{Y}, \sigma\right)$ is the sugar on the farm produced at prices and subsidy $\left(\bar{p}_{Y}, \sigma\right)$. Adding $v^{*}\left(\bar{p}_{Y}, 0\right)$ to both sides, and rearranging, we have

$$
v^{*}\left(\bar{p}_{Y}, 0\right)-v^{*}\left(p_{Y}, 0\right)+\sigma S^{*}\left(\bar{p}_{Y}, \sigma\right) \geq v^{*}\left(\bar{p}_{Y}, 0\right)-v^{*}\left(\bar{p}_{Y}, \sigma\right) .
$$

So, the loss in surplus from the subsidy is bounded above by the sum of $v^{*}\left(\bar{p}_{Y}, 0\right)-v^{*}\left(p_{Y}, 0\right)$, that is, the gain in producer surplus from higher prices, and the subsidy. So, at least as a matter of theory, the surplus loss can be bigger than the subsidy.

\footnotetext{
${ }^{46}$ Note that $v^{*}\left(p_{Y}^{N}, 0\right) \geq v^{*}\left(p_{Y}^{N}, \sigma\right)$ because the subsidy introduces a distortion.
} 
Other features of the cartel could have led, in theory, to large surplus losses. Consider the restriction on the entry of farmers. Suppose prices of land in some areas of California were increasing so much that sugar production was barely profitable (even with the higher cartel prices). The farmer had the option of staying in his current location or closing down. There was no option of moving production to a location where, say, land prices did not increase at all (say in North Dakota). Here, again, was a potentially significant loss in producer surplus. The cartel initially raised price, and producer surplus, but much may have been destroyed as the industry was prohibited from using less expensive land. This is reminiscent of arguments by Posner (1975) that the cost of monopoly would be larger than Harberger triangles.

How could such a distortionary system have been set up? Once the initial cartel plan was rejected, the industry had very little time to create the new plan - a matter of a few months. Hence, it's not surprising that the plan could have led to significant unforeseen distortions. The industry did dodge what likely would have been an even bigger distortion: paying farmers for the tons of beets they produced (and not the sugar they produced). The government had paid subsidies to farmers in the year before the cartel was formed (under the Agricultural Adjustment Act) based on tonnage of beets. The industry avoided this scheme. There is the question of why such a distortionary system was not changed. The cartel had many critics. The cartel may have feared that any attempts to make significant changes to the cartel's operation may have offered critics a good platform to lobby to shut it down. 


\section{Appendix A - Data Sources}

Figure 1. U.S. sugar prices. Raw sugar price is duty paid New York raw sugar price. For 1910-1973, from USDA (1974), Table 51 col 3. For 1974-2008, from USDA (2009), Table 4, calendar year average price. Census sugar price is Beet Sugar Processors (SIC 2063) price, from Census of Manufactures, various years. It's the value of refined sugar products shipments divided by tons of sugar produced. World Sugar price. Raw sugar price in Caribbean ports. From 1890-1921, it's the average price of raw sugar in public warehouses in Cuba, U.S. Cuban Sugar Council (1948), Table 15. For 1922-1973, from USDA (1974), Table 51 col. 4. From 1974-2008, USDA (2009), Table 3, calendar year average price. Price Index. From 1890-1929, Index of the General Price Level, NBER Macro History Database series 04051. Annual average of monthly data. From 1929-2008, GDP Deflator, Bureau of Economic Analysis (2009). Series grafted by re-basing each to $1929=100$.

Figure 2. U.S. sugar prices. Same as Figure 1. Coal Price. From 1923-1948, U.S. Bureau of Mines Mineral Yearbook, national average bituminous coal price, reported in Dix (1988) Appendix Table D. From 1949-2006 Energy Information Agency, Annual Energy Review 2006, Table 7.8. Tractor price. Quality adjusted tractor price from Manuelli and Seshadri (2004). Fertilizer Price Paid. Agricultural Prices Annual Summary, various years. Land price. Dollars per acre of farm real estate, USDA (2006).

Figure 3. Total Sugar Act payments, including abandonment and deficiency payments, to sugar-beet producers, USDA (1974) Table 68. Industry Revenues. Value of sugar shipments, Census of Manufactures. Values for 1935, 1937 and 1939 include the processing tax. The tax is removed by subtracting 0.535 cents per pound, which is the refined equivalent of 0.5 cent tax on raw value.

Figures 4 and 5. Tons of beets. For 1891-1959, tons of beets sliced. For 1960-2007, tons of beets produced. Both series on crop year basis. For 1891-1908, USDA (1967), Table 5. For 1909-1959, USDA (1967), Table 1. For 1960-1991, Sugar: Background for 1995 Farm Legislation, Appendix Table 2. For 1992-2007, USDA (2008). Refined sugar produced. Crop year basis. Same 
sources as beets. Sucrose Content. For 1891-1935, Statistical Abstract of the United States, various issues. For 1936-1940, USDA (1963), Table 7. For 1940-1973, USDA (1974), Table 6. For 1992-2005, Sugar and Sweeteners Outlook, SSS-251, January 29, 2008, Table 1.

Figure 6. California Sucrose Content. For 1909-1935: Statistical Abstract of the United States, various issues. For 1942-1968, California Sugar Beet Growers Association, mimeo, American Crystal archives. For 1975-2003, USDA - National Agricultural Statistics Service Quick Stats, http://www.nass.usda.gov/QuickStats.

Figures $7,8 \mathrm{~A}, 8 \mathrm{~B}, 9 \mathrm{~A}$, and 9B. The data on factories and companies primarily are from archival records at various libraries. Data for American Crystal before 1973 are from the American Crystal collection at the Minnesota History Center, St. Paul. Data beyond 1973 were generously supplied by the company. Amalgamated Sugar Company records are in the American Crystal collection. These have been supplemented with historical data from Charles Schmalz (who worked for the company). More recent data were supplied by Dennis Costesso. The data for Holly Sugar (Sydney, MT) were provided by the plant manager. Data for the Great Western Sugar Company are from the collection at the University of Colorado, Boulder, which includes the records of the Ohio Northern Sugar Company. Data for the Michigan Sugar Company are from its annual reports, many of which are in the American Crystal collection. Data for the Utah \& Idaho Sugar Company are from the Leonard Arrington collection at Utah State University. Data for Spreckels Sugar Company are from its archive at the University of the Pacific and from "Sweet Nostalgia: Spreckels Sugar, Spreckels, CA, 1898-1982," a history of Factory \#1.

Figures 10 and 11. Fertilizer and land prices. Same as in Figure 2.

Figure 12. Acres harvested to sugar beets. USDA 1967, 1974, and Quick Statistics. Appendix B - Proofs

Proof of Propositions 1 and 2. Recall equation (7). We'll first derive the first order conditions for $M$ and $L$. We then consider the first order conditions as a system of two equations in the two 
unknowns $m=M / L$ and $L$. The first order condition for $M$ is

$$
\sigma S_{M}+p_{Y}^{N} Y_{M}=p_{M}+p_{E} \frac{a_{T}}{a_{E}} T_{M}
$$

where subscripts denote partial derivatives. We can write $S_{M}=(S / M) \epsilon_{S, M}$, where $\epsilon_{S, M}$ is the elasticity of $S$ with respect to $M$, where $\epsilon_{S, M}=\lambda-\psi>0$, by assumption above. We can write $Y_{M}$ and $T_{M}$ in a similar way, where $\epsilon_{Y, M}=\lambda-\mu \psi>0$. Hence, we have

$$
\sigma(S / M) \epsilon_{S, M}+p_{Y}^{N}(Y / M) \epsilon_{Y, M}=p_{E} \frac{a_{T}}{a_{E}}(T / M) \epsilon_{T, M}+p_{M}
$$

Multiply both sides by $M / T$ and rearrange to get:

$$
\sigma z \epsilon_{S, M}+p_{Y}^{N} A_{F} a_{T} z^{\mu} \epsilon_{Y, M}=p_{E} \frac{a_{T}}{a_{E}} \epsilon_{T, M}+p_{M}(M / T)
$$

Consider the left hand side (LHS) of the above equation as a function of $m$. When $m=0$, the LHS takes the value

$$
\sigma \bar{z} \epsilon_{S, M}+p_{Y}^{N} A_{F} a_{T} \bar{z}^{\mu} \epsilon_{Y, M}
$$

where $\bar{z}$ is the upper bound for $z$. When $m$ increases, the LHS is flat for a while, then it begins to decrease, approaching zero in the limit. Consider the right hand side (RHS). The term $(M / T)$ behaves like a power function in $m$. It's zero at $m=0$, and is increasing in $m$. So, the RHS equals $p_{E} \frac{a_{T}}{a_{E}} \epsilon_{T, M}$ when $m=0$, and is increasing in $m$. Hence, if $p_{E}$ is small, there will be a unique solution to equation (12), call it $m^{*}$.

At this point, we can prove the comparative statics results. As $\sigma$ or $p_{Y}^{N}$ increase, the downward sloping "curve" above (the LHS of equation (12)) shifts up, and $m^{*}$ increases.

Next, consider the first order condition with respect to $L$. We have

$$
\sigma S_{L}+p_{Y}^{N} Y_{L}=r(L)\left(1+\epsilon_{r}\right)+p_{E} \frac{a_{T}}{a_{E}} T_{L}
$$

where $\epsilon_{r}$ is the elasticity of land price. We can write this as

$$
\sigma(S / L) \epsilon_{S, L}+p_{Y}^{N}(Y / L) \epsilon_{Y, L}-p_{E} \frac{a_{T}}{a_{E}}(T / L) \epsilon_{T, L}=r(L)\left(1+\epsilon_{r}\right)
$$


and as

$$
(T / L)\left\{\sigma z \epsilon_{S, L}+p_{Y}^{N} A_{F} a_{T} z^{\mu} \epsilon_{Y, L}-p_{E} \frac{a_{T}}{a_{E}} \epsilon_{T, L}\right\}=r(L)\left(1+\epsilon_{r}\right) .
$$

Again, we are thinking of solving a system of two equations, (12) and (13), in two unknowns, $m$ and $L$. The LHS of (13) is a function of $m$ and not $L$. Suppose we plot the LHS against $L$. Then it's a constant. If we plot the RHS against $L$, it equals $r(0)\left(1+\epsilon_{r}\right)$ at zero, and it's increasing. If $r(0)\left(1+\epsilon_{r}\right)$ is small, and $r^{\prime}(L) \geq \widetilde{r}>0$, then there is a unique intersection, and hence an $L^{*}$.

We have found a unique solution $\left(m^{*}, L^{*}\right)$ to the first order conditions under the assumptions in the text, and this solution is interior. To finish the proof we need to show that $\left(m^{*}, L^{*}\right)$ is a local maximizer. In particular, we need to show that $\pi_{M M}<0$ and $\pi_{M M} \pi_{L L}-\pi_{M L}^{2}>0$, where $\pi$ is profit in equation (7). To show this, it will be useful to have the following derivatives:

$$
\begin{aligned}
& S_{M}=A_{z} A_{T}(\lambda-\psi) M^{\lambda-\psi-1} L^{1-\lambda+\psi} \\
& S_{M M}=A_{z} A_{T}(\lambda-\psi)(\lambda-\psi-1) M^{\lambda-\psi-2} L^{1-\lambda+\psi}=(\lambda-\psi-1) M^{-1} S_{M} .
\end{aligned}
$$

Similarly, $T_{M M}=(\lambda-1) M^{-1} T_{M}$ and $Y_{M M}=(\lambda-\mu \psi-1) M^{-1} Y_{M}$. We then can write

$$
\begin{aligned}
\pi_{M} & =\sigma S_{M}+p_{Y}^{N} Y_{M}-p_{M}-p_{E} \frac{a_{T}}{a_{E}} T_{M} \\
\pi_{M M} & =\sigma S_{M M}+p_{Y}^{N} Y_{M M}-p_{E} \frac{a_{T}}{a_{E}} T_{M M} \\
& =(\lambda-\psi-1) M^{-1} \sigma S_{M}+(\lambda-\mu \psi-1) M^{-1} p_{Y}^{N} Y_{M}-(\lambda-1) M^{-1} p_{E} \frac{a_{T}}{a_{E}} T_{M} \\
& =(\lambda-1) M^{-1}\left(\sigma S_{M}+p_{Y}^{N} Y_{M}-p_{E} \frac{a_{T}}{a_{E}} T_{M}\right)-\psi M^{-1} \sigma S_{M}-\mu \psi M^{-1} p_{Y}^{N} Y_{M} \\
& =M^{-1}\left((\lambda-1) p_{M}-\psi \sigma S_{M}-\mu \psi p_{Y}^{N} Y_{M}\right)
\end{aligned}
$$

Note that $\lambda<1, S_{M}>0$ and $Y_{M}>0$, so $\pi_{M M}<0$.

Now we need to show of $\pi_{M M} \pi_{L L}-\pi_{M L}^{2}>0$. We'll use matrix notation. Let $A=$ $\left(\begin{array}{ccc}\sigma & p_{Y}^{N} & -p_{E} \frac{a_{T}}{a_{E}}\end{array}\right), H_{M M}=\left(\begin{array}{ccc}S_{M M} & Y_{M M} & T_{M M}\end{array}\right), H_{M L}=\left(\begin{array}{ccc}S_{M L} & Y_{M L} & T_{M L}\end{array}\right)$ and $H_{L L}=$ 
$\left(\begin{array}{ccc}S_{L L} & Y_{L L} & T_{L L}\end{array}\right)$. We can write (where ()$^{T}$ denotes the transpose of a matrix)

$$
\begin{aligned}
& \pi_{M M}=A \cdot H_{M M}^{T} \\
& \pi_{M L}=A \cdot H_{M L}^{T} \\
& \pi_{L L}=A \cdot H_{L L}^{T}-r^{\prime}(L)\left(1+\epsilon_{r}\right)
\end{aligned}
$$

Therefore,

$$
\begin{aligned}
\pi_{M M} \pi_{L L}-\pi_{M L}^{2} & =\left(A \cdot H_{M M}^{T}\right) \cdot\left(A \cdot H_{L L}^{T}\right)^{T}-\left(A \cdot H_{M L}^{T}\right) \cdot\left(A \cdot H_{M L}^{T}\right)^{T}-r^{\prime}(L)\left(1+\epsilon_{r}\right) \pi_{M M} \\
& =A \cdot\left(H_{M M}^{T} \cdot H_{L L}-H_{M L}^{T} \cdot H_{M L}\right) \cdot A^{T}-r^{\prime}(L)\left(1+\epsilon_{r}\right) \pi_{M M}
\end{aligned}
$$

We can show that $H_{M M}^{T} \cdot H_{L L}=H_{M L}^{T} \cdot H_{M L}$. In other words, we can show

$$
\left(\begin{array}{ccc}
S_{M M} S_{L L} & S_{M M} Y_{L L} & S_{M M} T_{L L} \\
Y_{M M} S_{L L} & Y_{M M} Y_{L L} & Y_{M M} T_{L L} \\
T_{M M} S_{L L} & T_{M M} Y_{L L} & T_{M M} T_{L L}
\end{array}\right)=\left(\begin{array}{ccc}
S_{M L} S_{M L} & S_{M L} Y_{M L} & S_{M L} T_{M L} \\
Y_{M L} S_{M L} & Y_{M L} Y_{M L} & Y_{M L} T_{M L} \\
T_{M L} S_{M L} & T_{M L} Y_{M L} & T_{M L} T_{M L}
\end{array}\right) .
$$

For instance,

$$
S_{M M} S_{L L}=A_{z}^{2} A_{T}^{2}(\lambda-\phi)^{2}(1-\lambda+\psi) M^{2(\lambda-\psi-1)} L^{2(-\lambda+\psi)}=S_{M L}^{2}
$$

The other eight equalities can be similarly proven. So,

$$
\pi_{M M} \pi_{L L}-\pi_{M L}^{2}=-r^{\prime}(L)\left(1+\epsilon_{r}\right) \pi_{M M}
$$

Since $r^{\prime}(\cdot)>0$ and $\pi_{M M}<0, \pi_{M M} \pi_{L L}-\pi_{M L}^{2}>0$, and the Hessian matrix is negative semi-definite. Proof of Proposition 3. Let's compare two policies, one of which offers the firm a "small" amount $\Delta \varepsilon_{1}$ for each unit of $S$ produced, and the other offers $\Delta \varepsilon_{2}$ for each unit of $Y$ produced. We want to compare the distortion (the increase in $m$ ) in the two cases. We want both policies to "cost" the same, that is, we choose $\Delta \varepsilon_{1}$ and $\Delta \varepsilon_{2}$ so that $\Delta \varepsilon_{1} S=\Delta \varepsilon_{2} Y$. 
In the first policy, materials are increased by approximately $\Delta \varepsilon_{1} m_{\sigma}$, since $m_{\sigma}$ is the change in materials given an infinitesimal small change in subsidy. In the second policy, materials are increased by $\Delta \varepsilon_{2} m_{p_{Y}^{N}}$. The increase in materials in the first policy relative to the second is

$$
\frac{\Delta \varepsilon_{1} m_{\sigma}}{\Delta \varepsilon_{2} m_{p_{Y}^{N}}}=\frac{m_{\sigma}}{m_{p_{Y}^{N}}} \frac{Y}{S}
$$

where we have used $\Delta \varepsilon_{1} S=\Delta \varepsilon_{2} Y$. To calculate $m_{\sigma}$ and $m_{p_{Y}^{N}}$, write equation (12) as

$$
H\left(\sigma, p_{Y}^{N}, m\left(\sigma, p_{Y}^{N}\right)\right)=0
$$

where $m\left(\sigma, p_{Y}^{N}\right)$ is the solution to the equation for $m$. Totally differentiating this equation with respect to $\sigma$ and $p_{Y}^{N}$ we have

$$
H_{\sigma}+H_{m} m_{\sigma}=0 \text { and } H_{p_{Y}}+H_{m} m_{p_{Y}}=0 .
$$

We then have that

$$
\frac{m_{\sigma}}{m_{p_{Y}^{N}}}=\frac{H_{\sigma}}{H_{p_{Y}^{N}}}=\frac{z}{A_{F} a_{T} z^{\mu}} \frac{\varepsilon_{S, M}}{\varepsilon_{Y, M}}=\frac{S}{Y} \frac{\left(\varepsilon_{T, M}-\left|\varepsilon_{z, M}\right|\right)}{\left(\varepsilon_{T, M}-\mu\left|\varepsilon_{z, M}\right|\right)} .
$$

Hence, we have (since $\mu \geq 1$ )

$$
\frac{m_{\sigma}}{m_{p_{Y}}} \frac{Y}{S}=\frac{\left(\varepsilon_{T, M}-\left|\varepsilon_{z, M}\right|\right)}{\left(\varepsilon_{T, M}-\mu\left|\varepsilon_{z, M}\right|\right)} \geq 1
$$

Hence, subsidizing $S$ has a bigger (negative) impact on quality than does subsidizing $Y$. 


\section{References}

[1] Ballinger, Roy. 1974. A History of Sugar Marketing through 1974. Washington, DC: U.S. Department of Agriculture/Economics, Statistics, and Cooperatives Service.

[2] Bloom, Nicholas, Draca, M. and Van Reenen, John. 2008. "Trade Induced Technological Change? The Impact of Chinese Imports on IT and Innovation." Mimeo.

[3] Bridgman, Benjamin, Qi, Shi and Schmitz, James. 2007. "Does Regulation Reduce Productivity? Evidence From Regulation of the U.S. Beet-Sugar Manufacturing Industry During the Sugar Acts, 1934-74." Research Department Staff Report 389. Federal Reserve Bank of Minneapolis.

[4] Caves, Jonathan and Salant, Stephen. 1995. "Cartel Quotas Under Majority Rule." American Economic Review, Vol. 85, No. 1 (March), pp. 82-102.

[5] Cole, Harold L. and Ohanian, Lee E. 2004. "New Deal Policies and the Persistence of the Great Depression: A General Equilibrium Analysis." Journal of Political Economy, Vol. 112, No. 4 (August), pp. 779-816.

[6] Dix, Keith. 1988. What's a Coal Miner to Do? The Mechanization of Coal Mining. Pittsburgh: University of Pittsburgh Press.

[7] Dye, Alan. 1994. "Avoiding Holdup: Asset Specificity and Technical Change in the Cuban Sugar Industry, 1899-1929." Journal of Economic History, Vol. 54, No. 3 (Sept.), pp. 628-653.

[8] Fabrizio, Kira R., Rose, Nancy L., and Wolfram, Catherine D. 2007. "Do Markets Reduce Costs? Assessing the Impact of Regulatory Restructuring on U.S. Electric Generation Efficiency." American Economic Review, Vol. 97, No. 4 (Sept.), pp. 1250-1277. 
[9] Galdón-Sánchez, José E. and Schmitz, James A., Jr. 2002. "Competitive Pressure and Labor Productivity: World Iron-Ore Markets in the 1980s." American Economic Review, Vol. 92, No. 4 (Sept.), pp. 1222-1235.

[10] Gale, Johnson, D. April 1974. The Sugar Program: Large Costs and Small Benefits. Washington, DC: American Enterprise Institute for Public Policy Research.

[11] Genesove, David and Mullin, Wallace P. 2001. "Rules, Communication, and Collusion: Narrative Evidence from the Sugar Institute Case." American Economic Review, Vol. 91, No. 3, pp. 379-398.

[12] Haley, Stephen and Ali, Mir. July 2007. Sugar Backgrounder. 555-249-01. U.S. Department of Agriculture, Economic Research Service.

[13] Herder, Richard. May 1964. "Sugar Beets: The District's Potential." Federal Reserve Bank of Minneapolis, Monthly Review.

[14] Heston, Thomas. 1987. Sweet Subsidy: The Economic and Diplomatic Effects of the U.S. Sugar Acts 1934-74. New York: Garland Publishing.

[15] Hexem, Roger and Heady, Earl. 1978. Water Production Functions for Irrigated Agriculture. Ames: Iowa State University Press.

[16] Hoff, Frederic. September 1984. Sugar: Background for the 1985 Farm Legislation. USDA Agriculture Information Bulletin 478.

[17] Holmes, Thomas and Schmitz, James A., Jr. 2001. "Competition at Work: Railroads vs. Monopoly in the U.S. Shipping Industry." Federal Reserve Bank of Minneapolis Quarterly Review, Vol. 25, No. 2 (Spring), pp. 3-29. 
[18] Hsieh, Chang-Tai and Klenow, Peter. 2008. "Misallocation and Manufacturing TFP in China and India." Mimeo, Standford University.

[19] Koenig, Jeanine. 1996. "Vertical Integration and Contracts: Application to the U.S. Beet Sugar Industry." Ph.D. dissertation, Washington University, St. Louis.

[20] Levenstein, Margaret C. and Suslow, Valerie Y. 2006. "What Determines Cartel Success?" Journal of Economic Literature, Vol. 44, No. 1 (March), pp. 43-95.

[21] Lord, Ron. 1994. "The Beet Industry of Minnesota and North Dakota: Current Situation and Prospects." Sugar and Sweetener Situation and Outlook, Vol. 19, No. 3 (Sept.).

[22] Manuelli, Rodolfo and Seshadri, Ananth. September 2004. "Frictionless Technology Diffusion: The Case of Tractors." Mimeo.

[23] Porter, Michael E. and Sakakibara, Mariko. 2004. "Competition in Japan.” Journal of Economic Perspectives, Vol. 18, No. 1 (Winter), pp. 27-50.

[24] Porter, Michael E. and Takeuchi, Hirotaka. 1999. "Fixing What Really Ails Japan." Foreign Affairs, May-June.

[25] Posner, Richard A. 1975. "The Social Costs of Monopoly and Regulation." Journal of Political Economy, Vol. 83, No. 4 (Aug.), pp. 807-827.

[26] Prescott, Edward C. 1998. "Needed: A Theory of TFP." International Economic Review, Vol. 39, No. 3 (Aug.), pp. 525-551.

[27] Roller, Lars-Hendrik and Steen, Frode. 2006. "On the Workings of a Cartel: Evidence from the Norwegian Cement Industry." American Economic Review, Vol. 96, No. 1 (March) pp. 321-338. 
[28] Schmitz, James. 2005. "What Determines Productivity? Lessons from the Dramatic Recovery of the U.S. and Canadian Iron Ore Industries Following Their Early 1980s Crisis." Journal of Political Economy, Vol. 113, No. 3, (June), pp. 582-625.

[29] Shoptaugh, Terry. 1997. Roots of Success: History of the Red River Valley Sugarbeet Growers. North Dakota State University, Institute for Regional Studies.

[30] Stigler, George J. "The Theory of Economic Regulation." Bell Journal of Economics, Vol. 2, No. 1 (Spring), pp. 3-21.

[31] Symeonidis, George. 2008. "The Effect of Competition on Wages and Productivity: Evidence from the United Kingdom." Review of Economics and Statistics, Vol. 90, No. 1 (Feb.), pp. 134-146.

[32] Syverson, Chad. 2004. "Market Structure and Productivity: A Concrete Example." Journal of Political Economy, Vol. 112, No. 6 (Dec.), pp. 1181-1222.

[33] Timoshenko, V. and Swerling, B. 1957. The World's Sugar. Stanford, CA: Stanford University Press, Food Research Institute.

[34] United States Cuban Sugar Council. 1948. Sugar: Facts and Figures. New York: United States Cuban Sugar Council.

[35] United States Department of Agriculture. 1939. "Preliminary Report With Respect to Processor-Grower Relations in the U.S. Sugar Beet Industry." Sugar Division. Report Misc1.

[36] —. December 1963. Sugar Statistics and Related Data. Statistical Bulletin \# 244.

[37] - October 1967. Sugarbeets. Statistical Bulletin \# 413.

[38] - December 1974. Sugar Statistics and Related Data. Statistical Bulletin \# 293. 
[39] —. October 1991. "U.S. Sugar Statistical Compendium.” http://www.ers.usda.gov/data/ archive/91006/ (accessed March 2, 2009).

[40] —. August 4, 2006. "Agricultural Land Values and Cash Rents Annual Summary." http:// usda.mannlib.cornell.edu/reports/nassr/other/plr-bb/ (accessed December 11, 2006).

[41] - October 1, 2007. "Historic Costs and Returns, United States and ERS Production Regions, Old Format and Regions."

[42] —. 2009. "Sugar and Sweeteners Yearbook Tables." http://www.ers.usda.gov/Briefing/ Sugar/data.htm (accessed March 2, 2009).

[43] United States Department of Commerce. 2009. "Current-Dollar and "Real" Gross Domestic Product." http://www.bea.gov/national/xls/gdplev.xls (accessed March 2, 2009).

[44] United States Tariff Commission. Costs of Producing Sugar Beets, 1921, 1922, and 1923. 
Figure 1

\section{U.S. and World Sugar Prices}

(Relative to GDP Deflator)

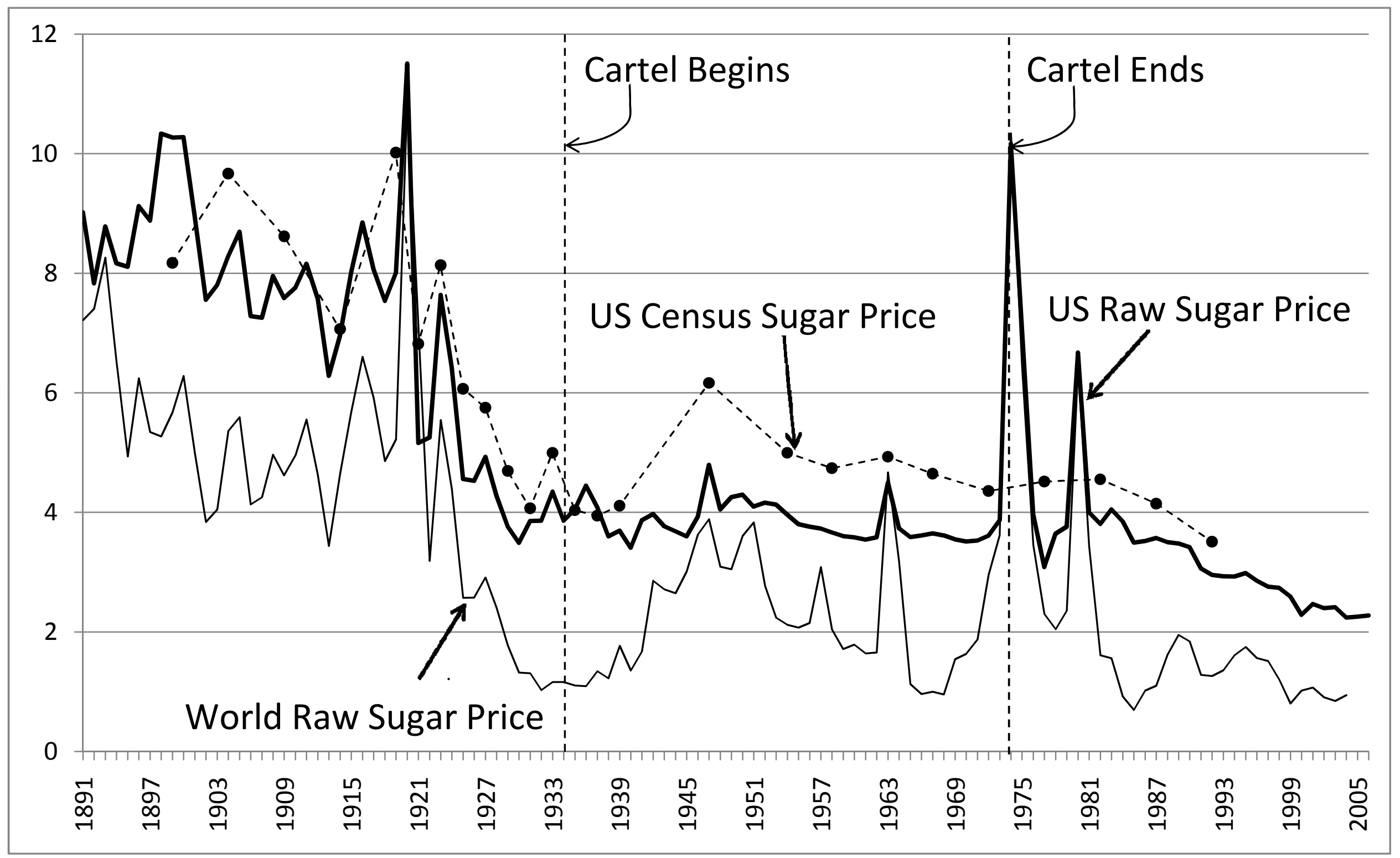




\section{Figure 2}

\section{Price of Sugar Relative to Price of Major Inputs}

Fertilizer

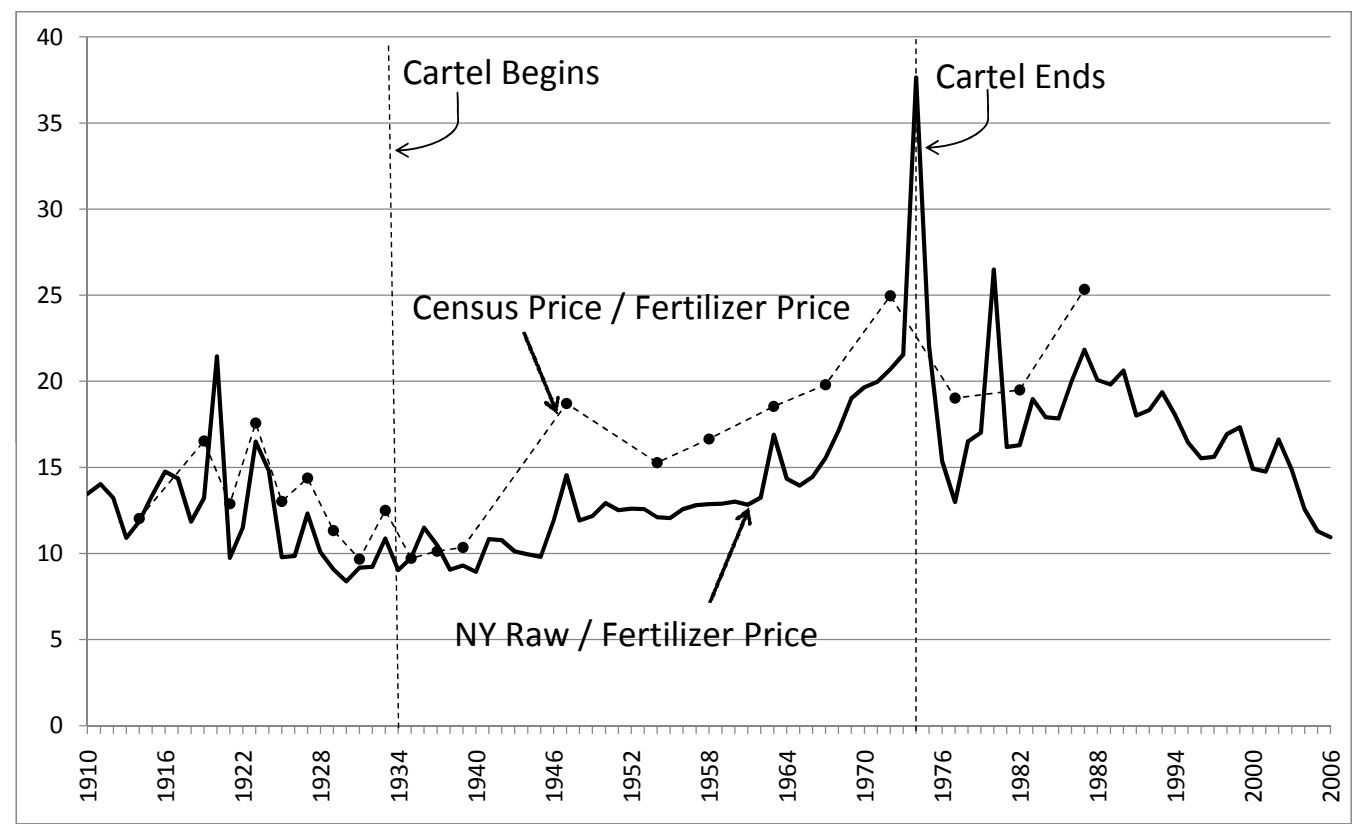

Land

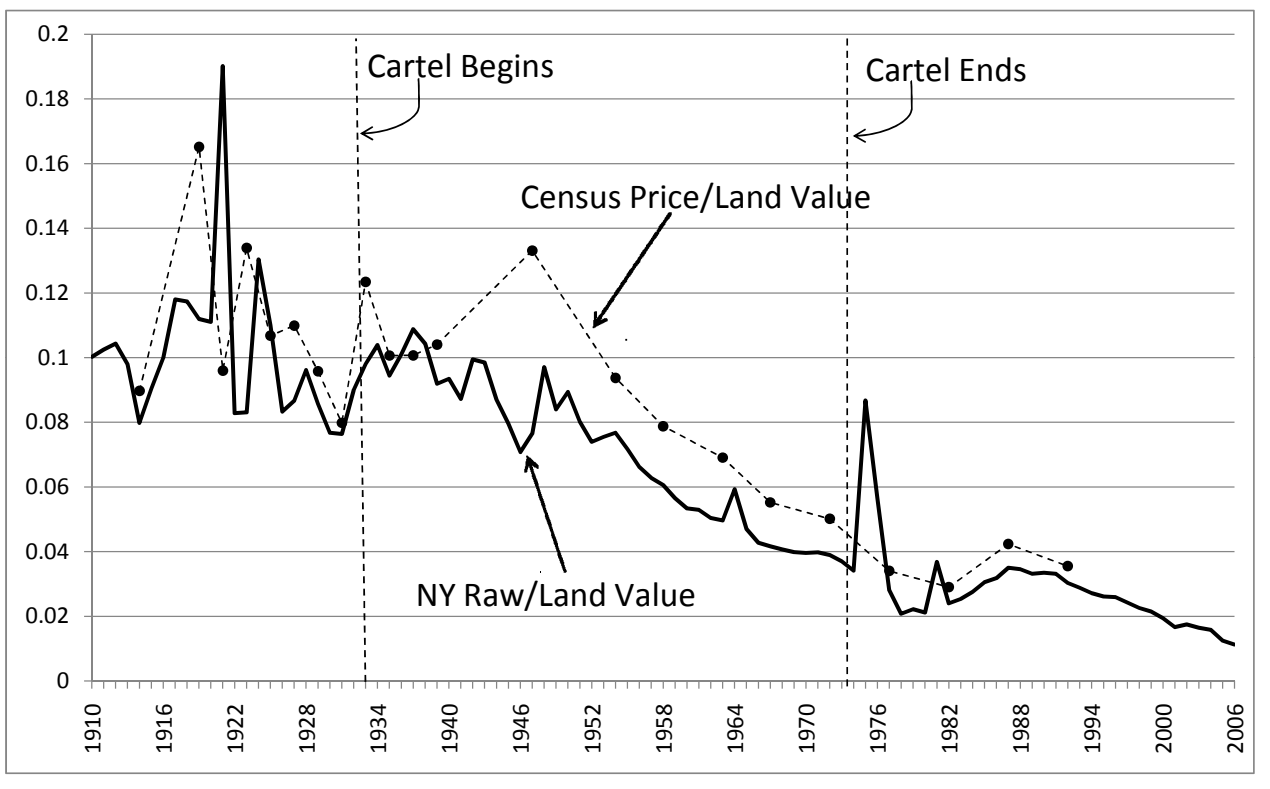

Coal

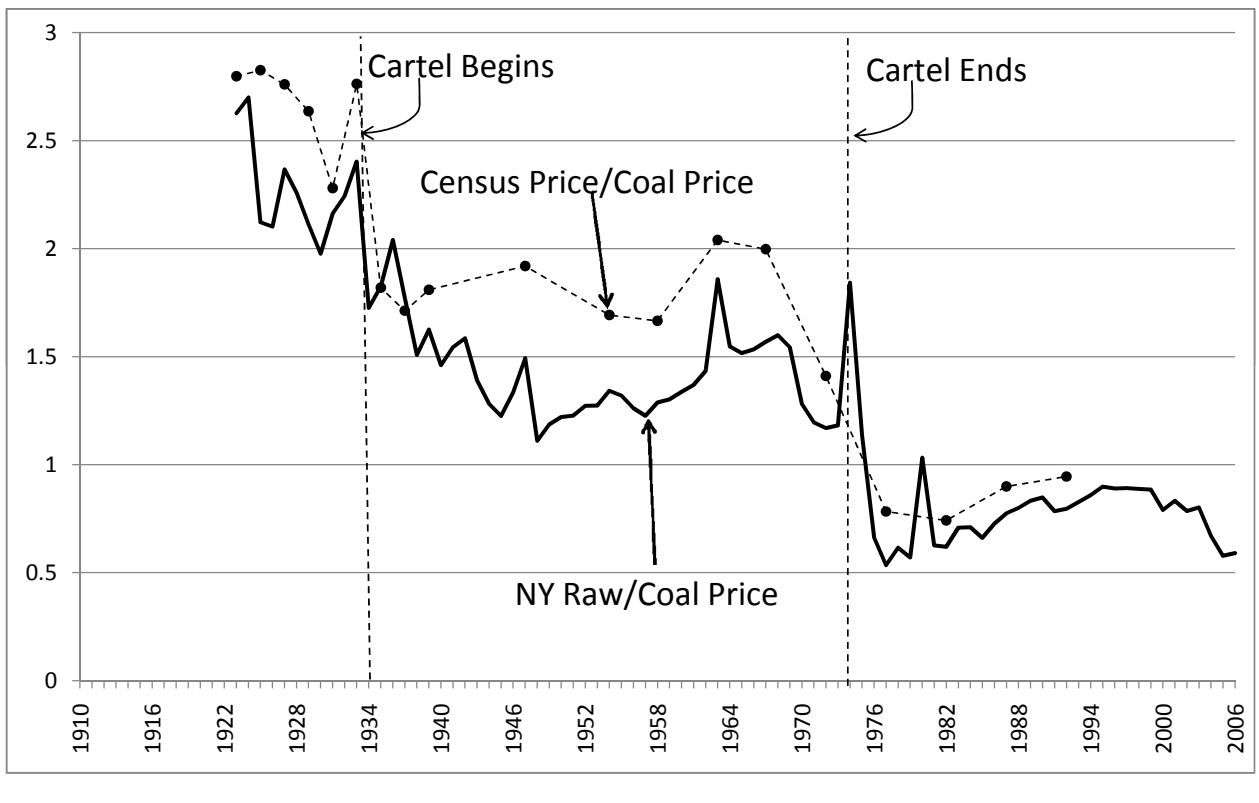

Farm Capital

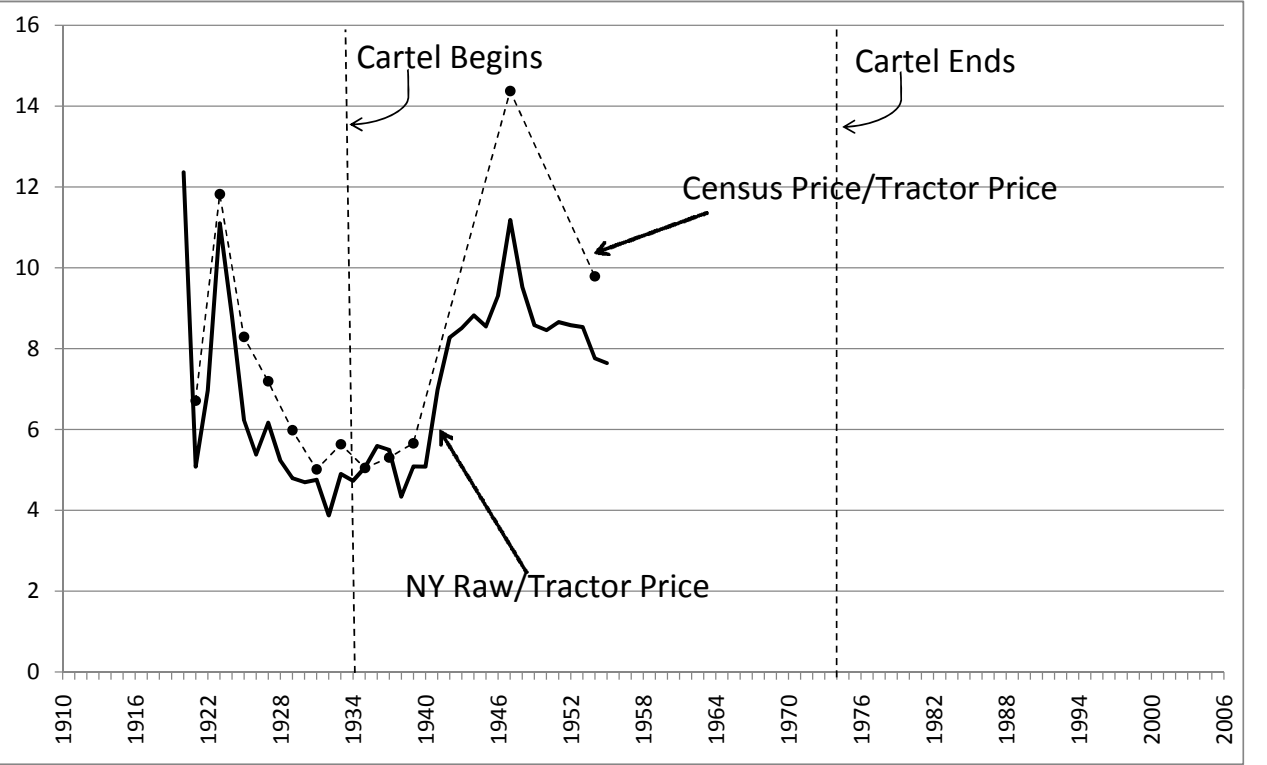


Figure 3

Total Industry Subsidies Relative to Industry Revenue (In Percent)

Beet-Sugar Manufacturing

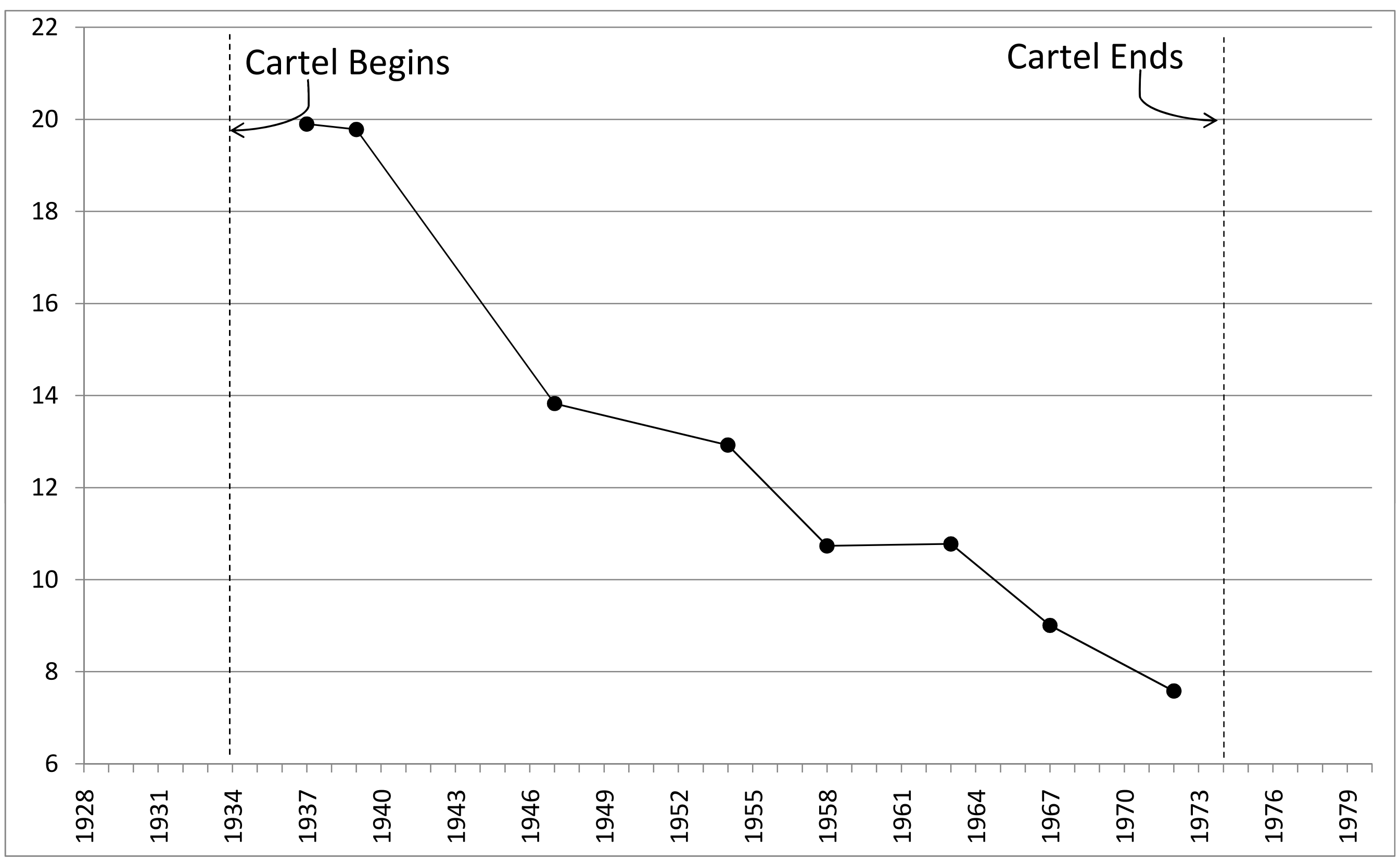


Figure 4

Pounds of Manufactured Sugar Per Ton of Beets US Recovery Rate

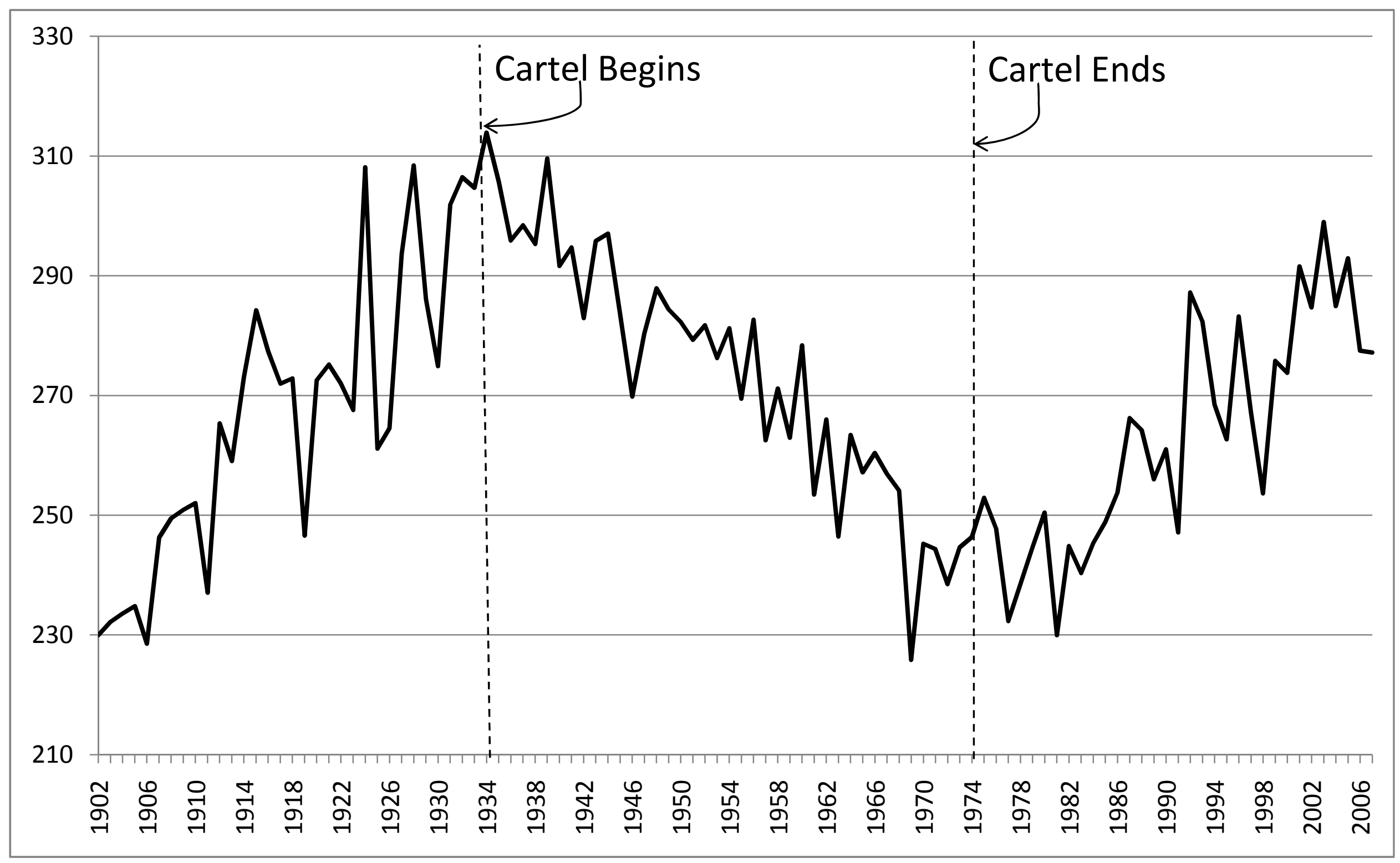


Figure 5

\section{US Sugar Content and US Extraction Rate}

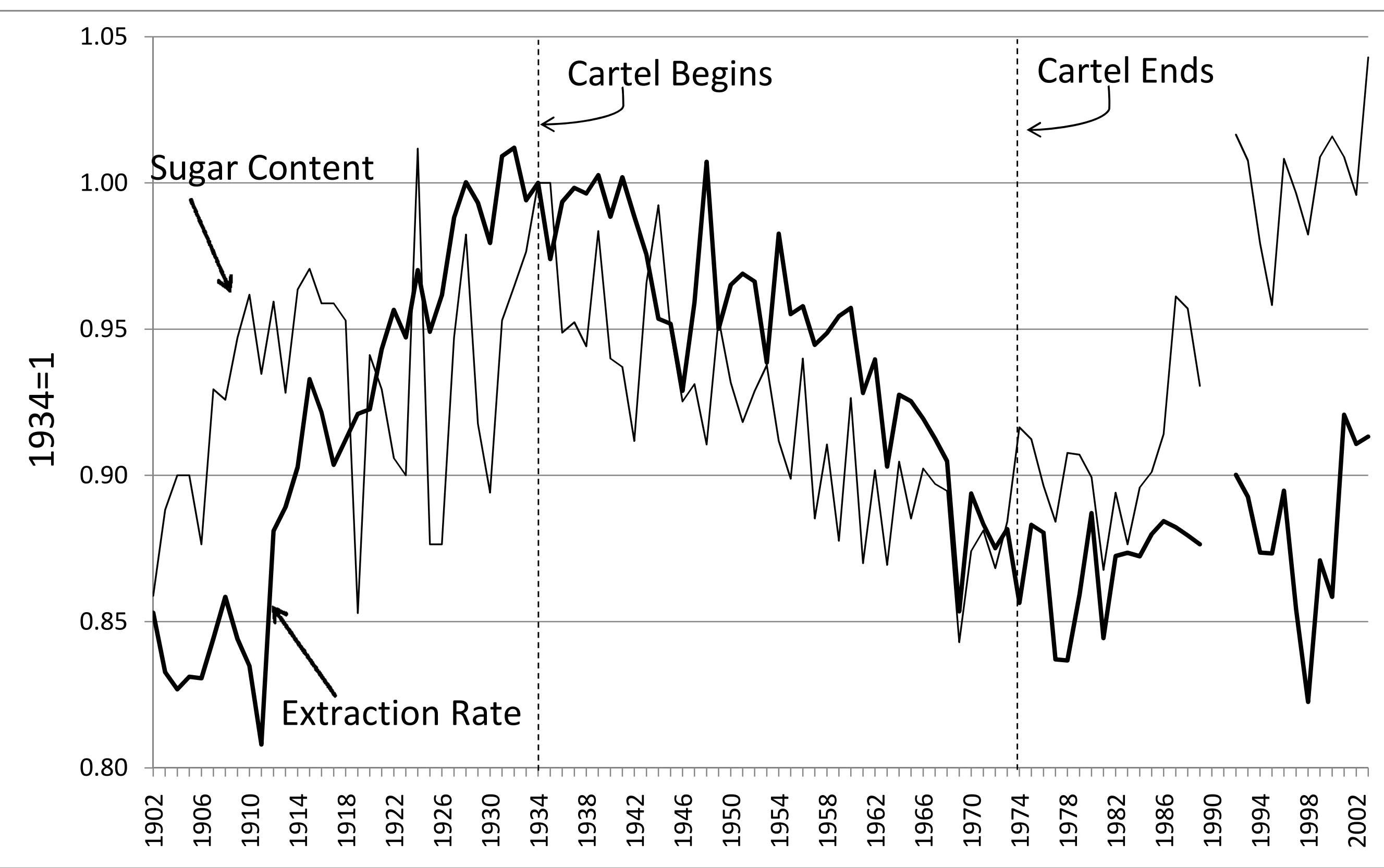




\section{Figure 6}

\section{Sugar Content: U.S. vs. California}

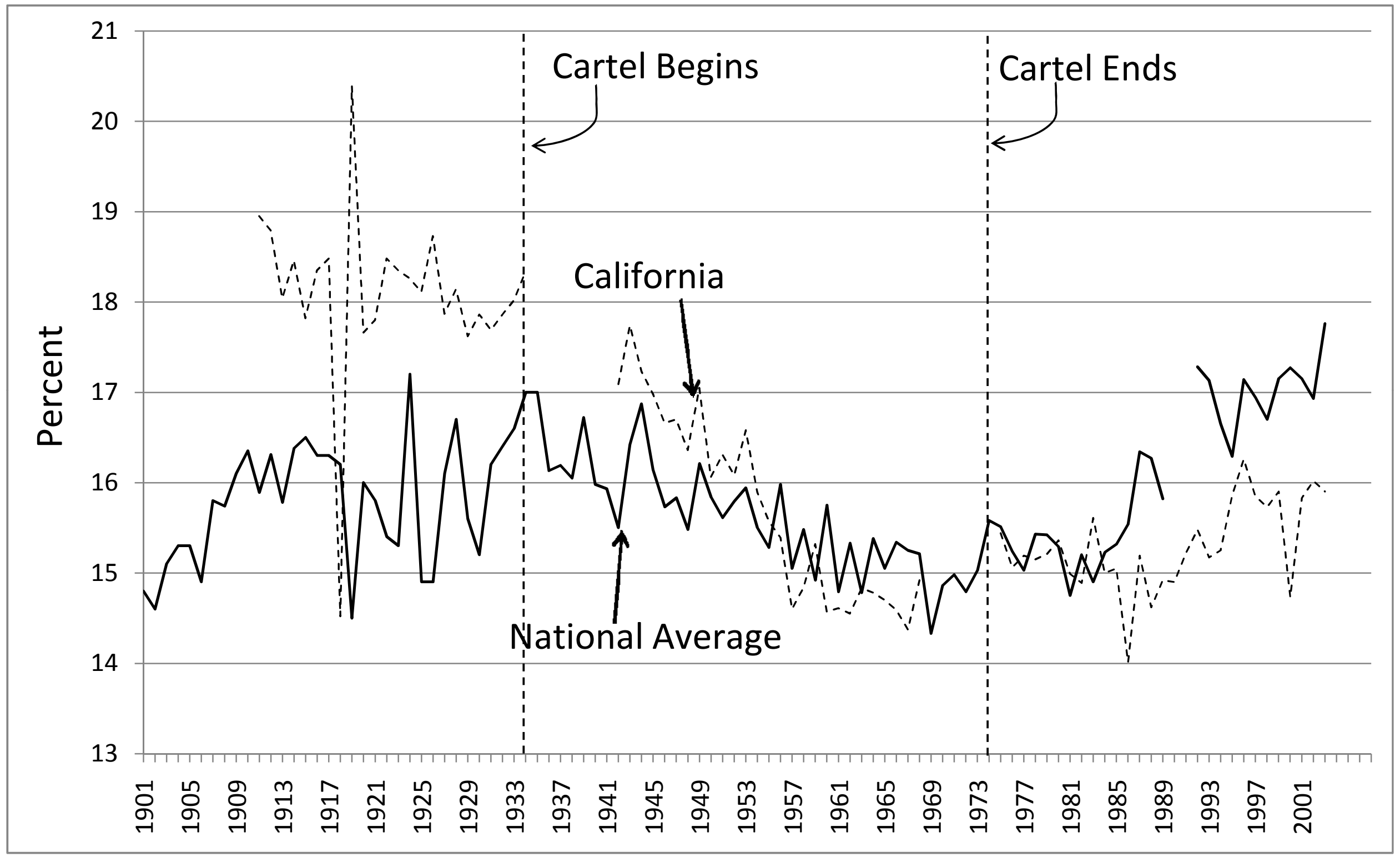




\section{Figure 7 \\ Sugar Content \\ (California Factories)}

Spreckels \#1

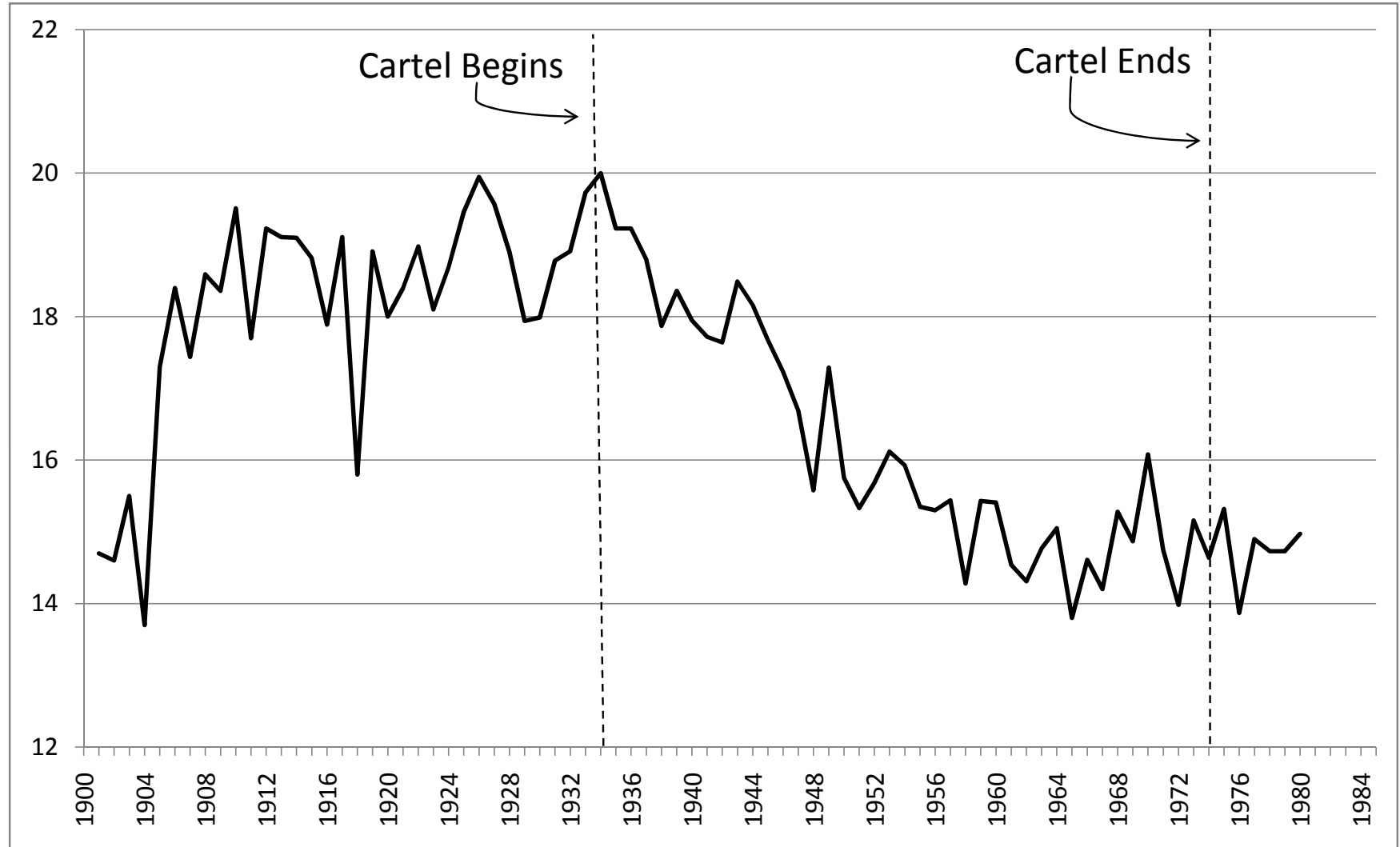

Oxnard

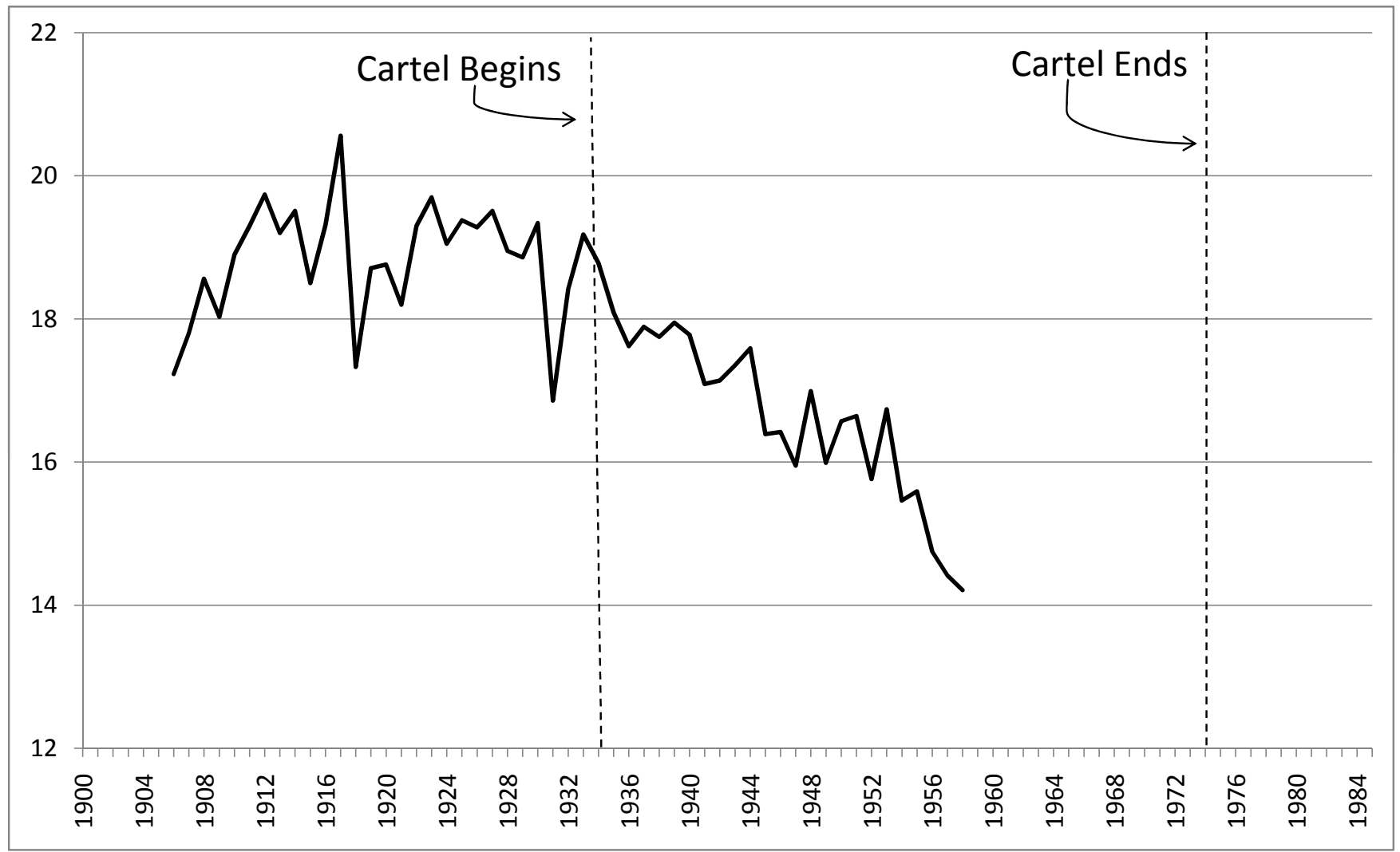




\section{Figure 8A}

\section{Pounds of Manufactured Sugar Per Ton of Beets Recovery Rate by Company}

American Crystal (West Factories)

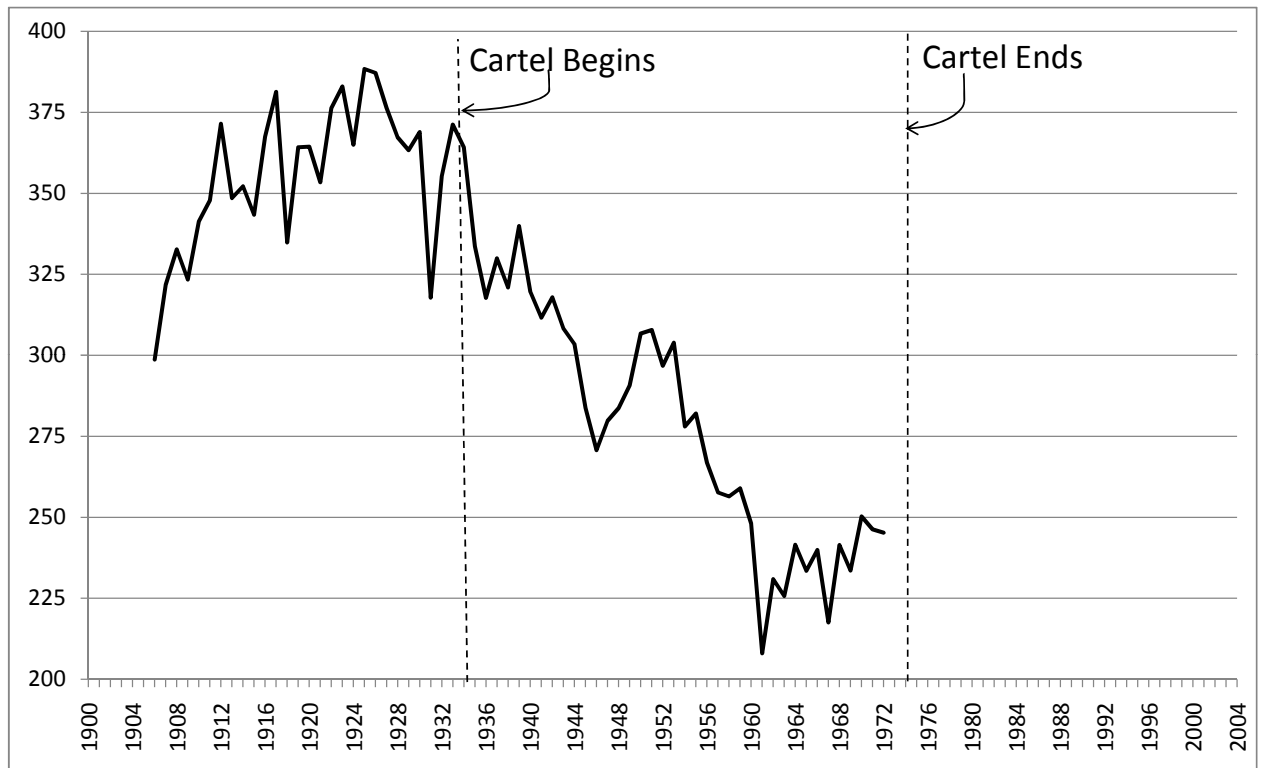

Utah\&Idaho Company

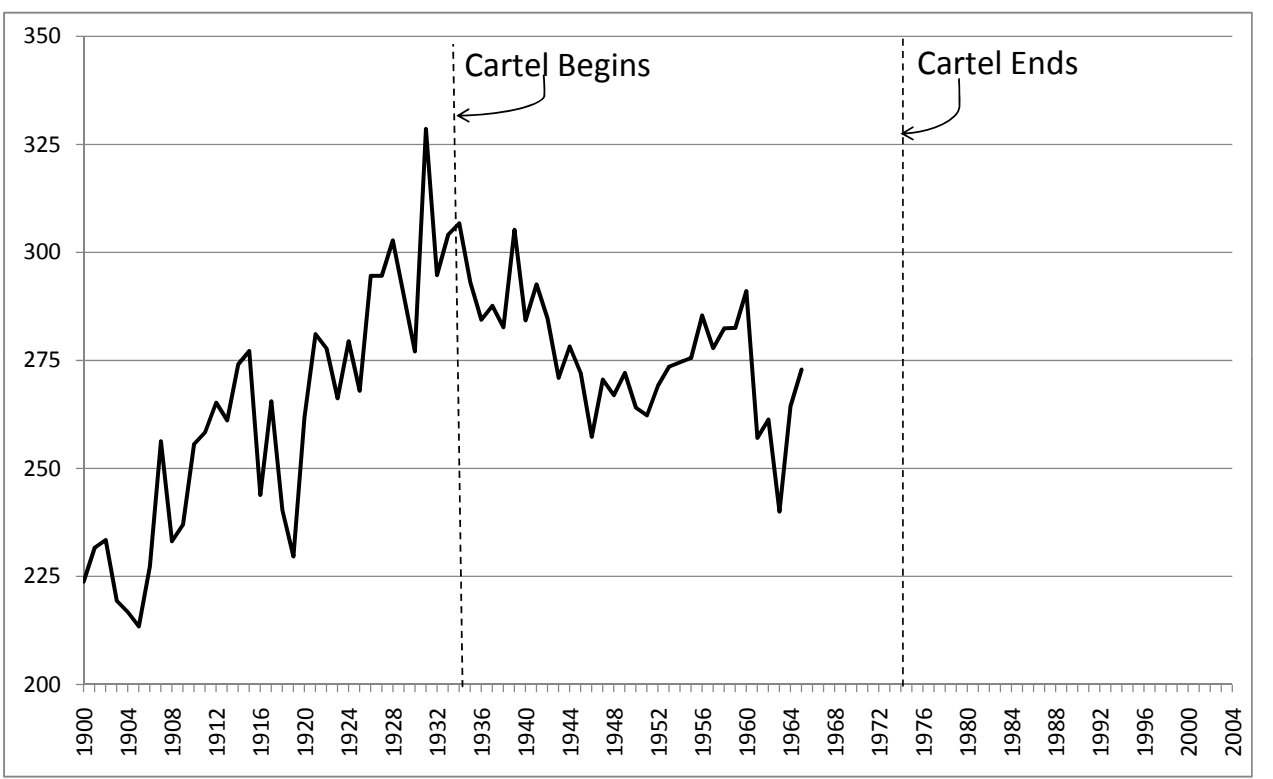

Spreckels

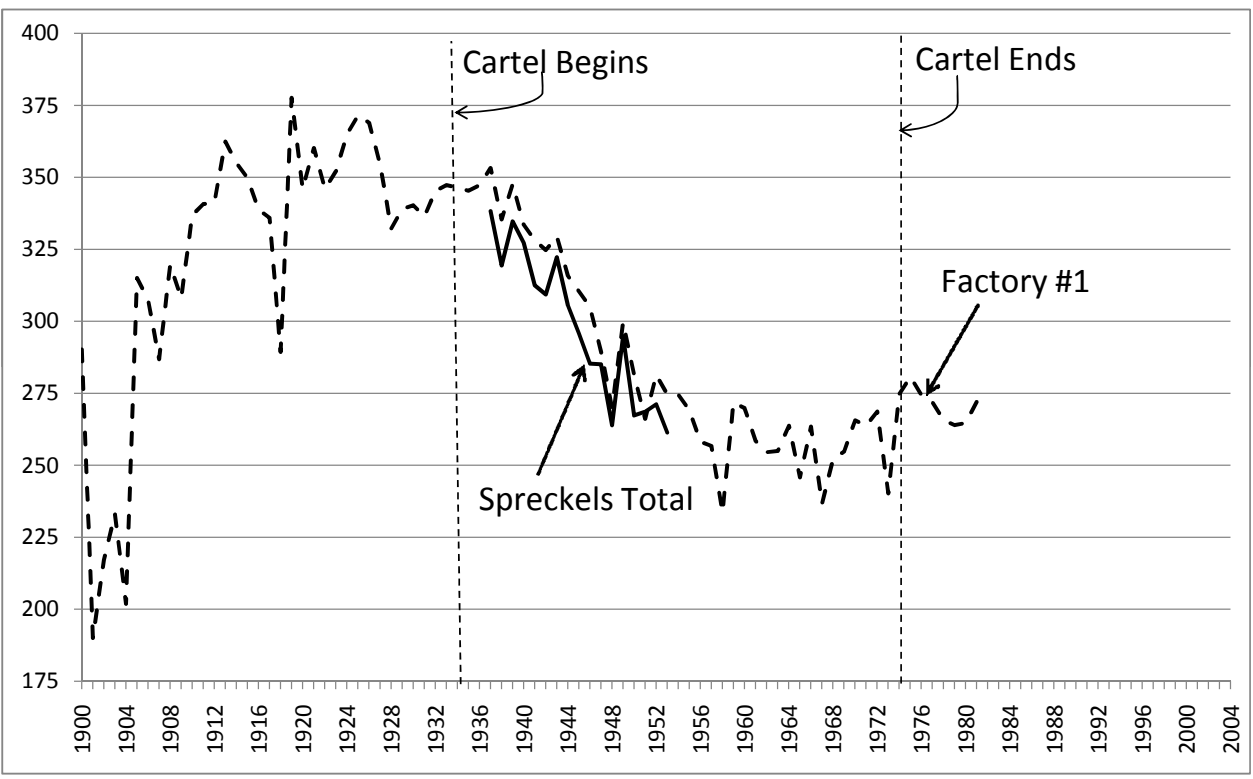

Amalgamated

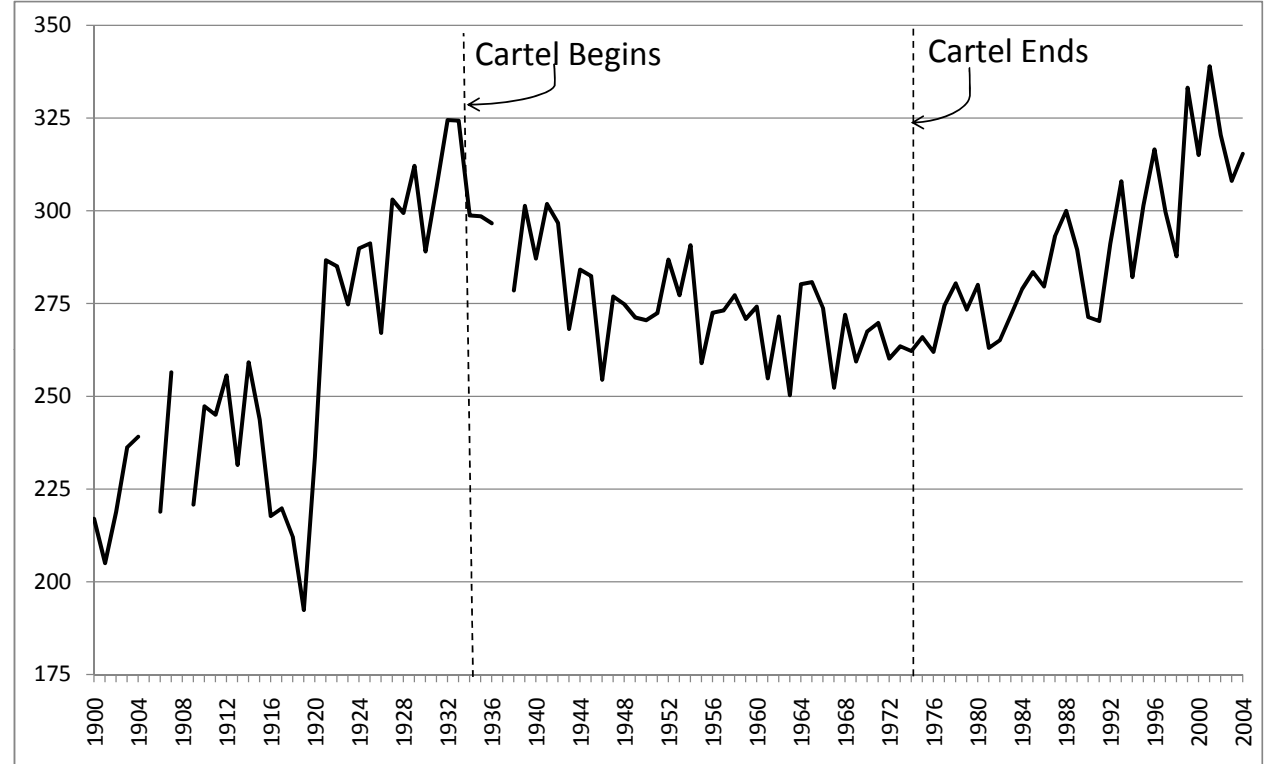




\section{Figure 8B}

\section{Pounds of Manufactured Sugar Per Ton of Beets Recovery Rate by Company}

Great Western

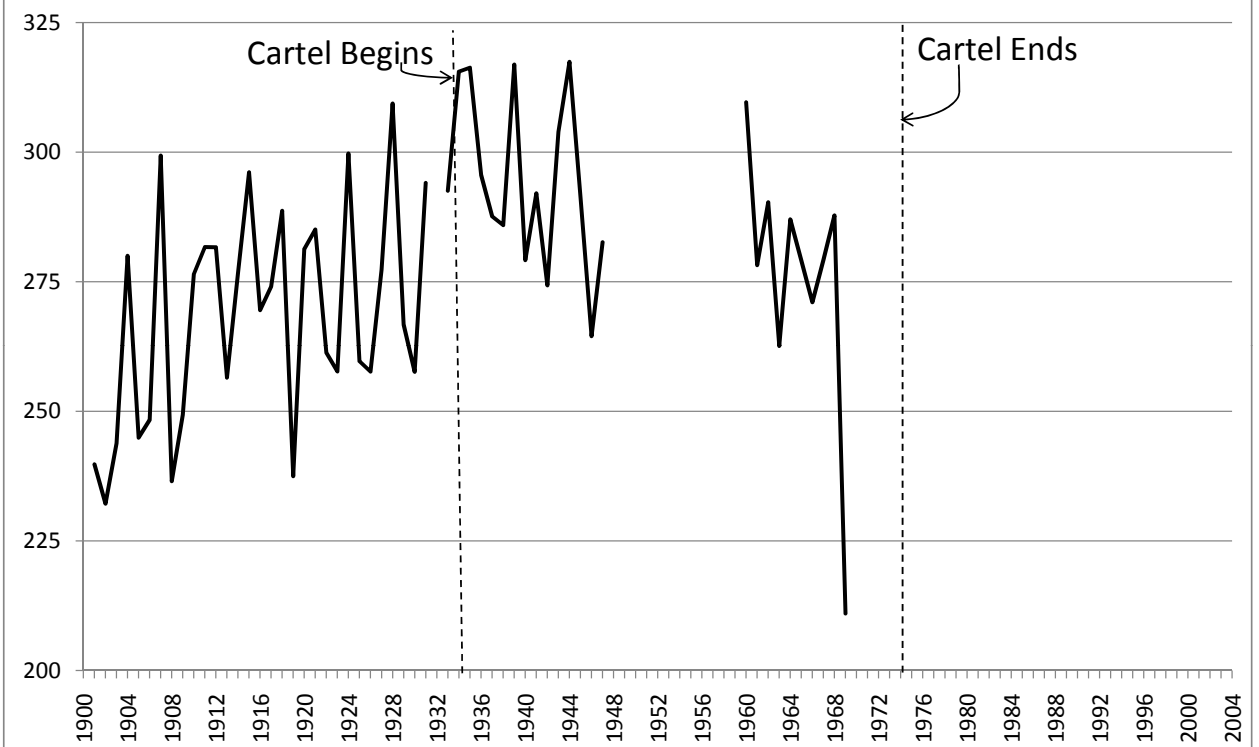

American Crystal (Red River Valley Factories)

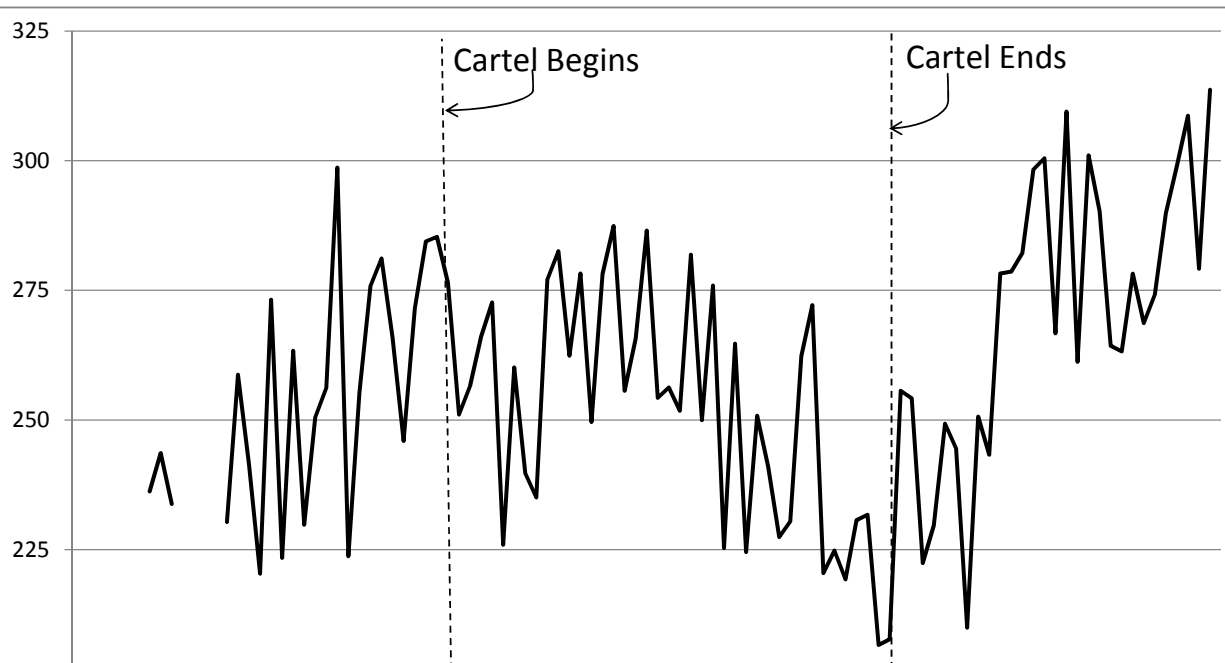

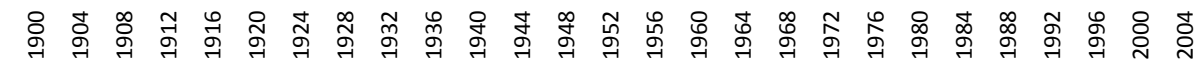

Holly

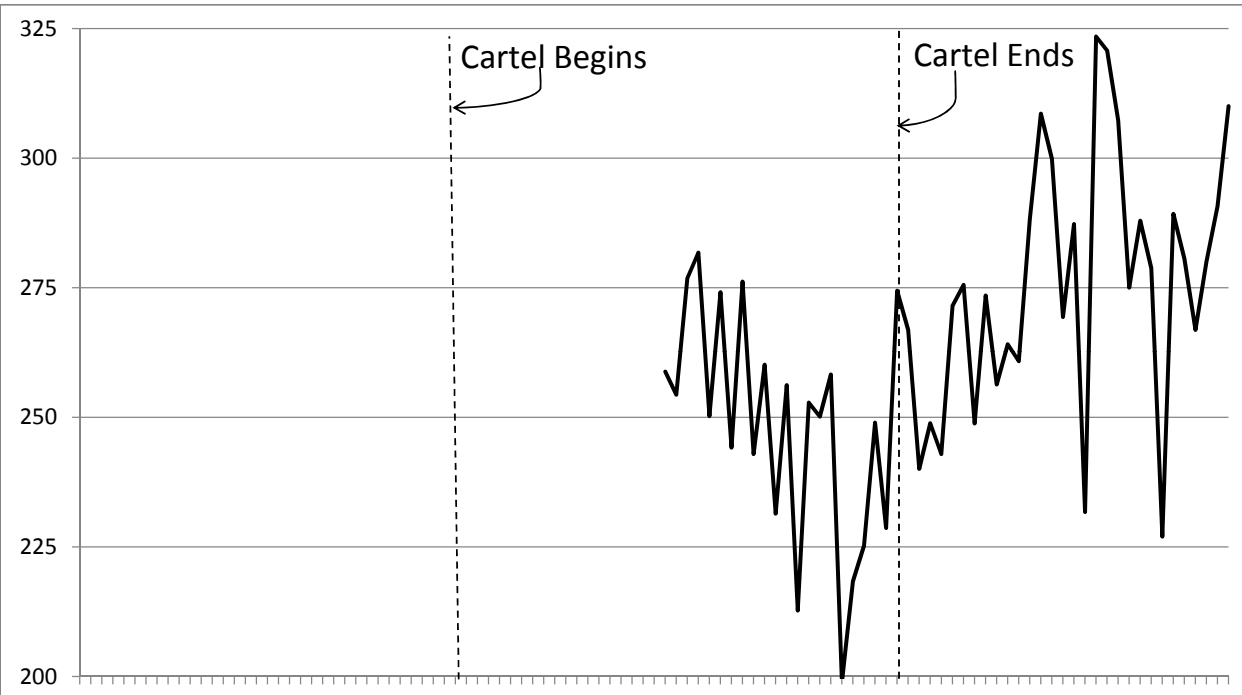

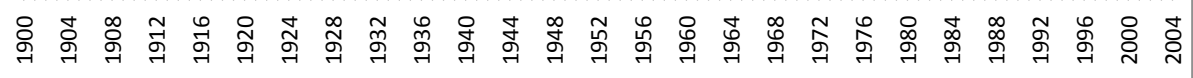

Michigan Sugar Company

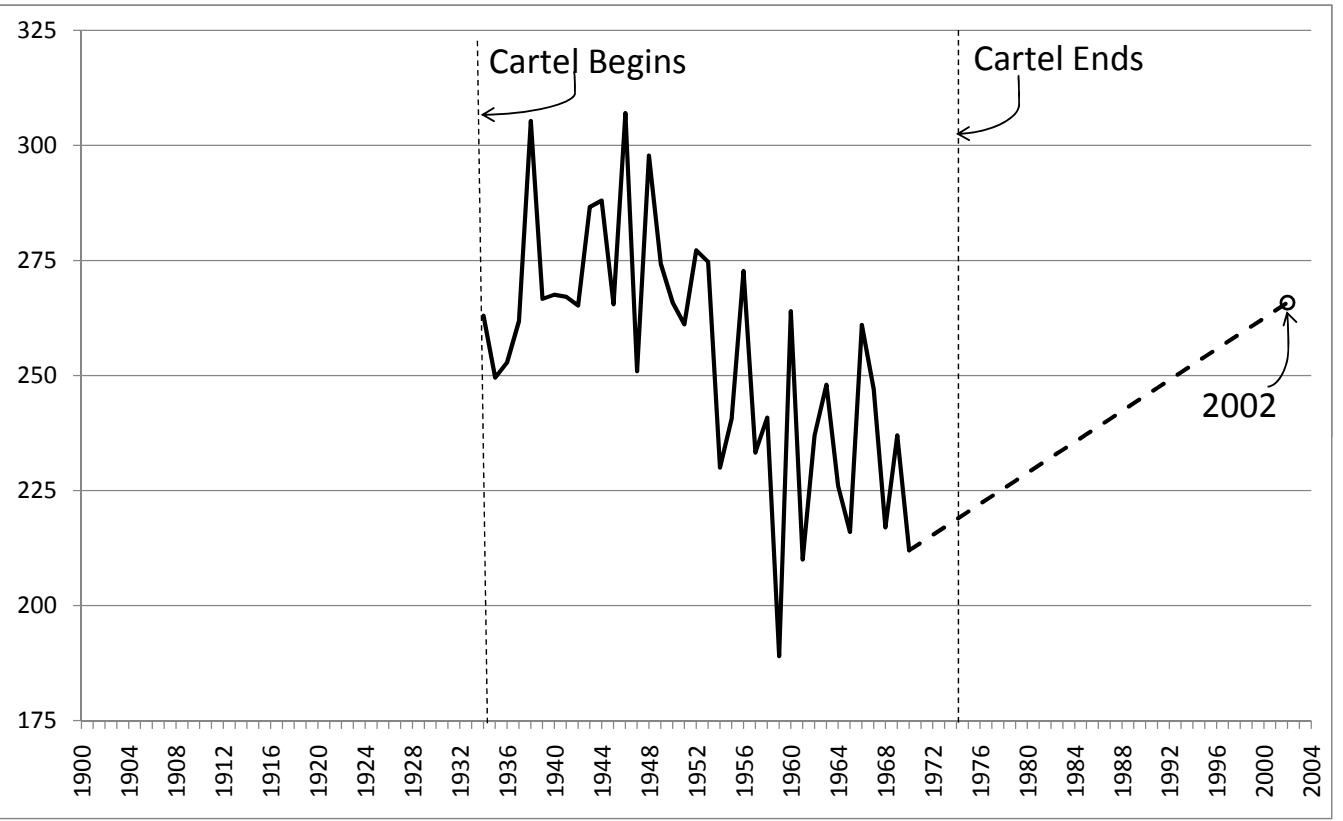


Figure 9A

Pounds of Manufactured Sugar Per Ton of Beets Recovery Rate - West Factories

Oxnard, CA (American Crystal)

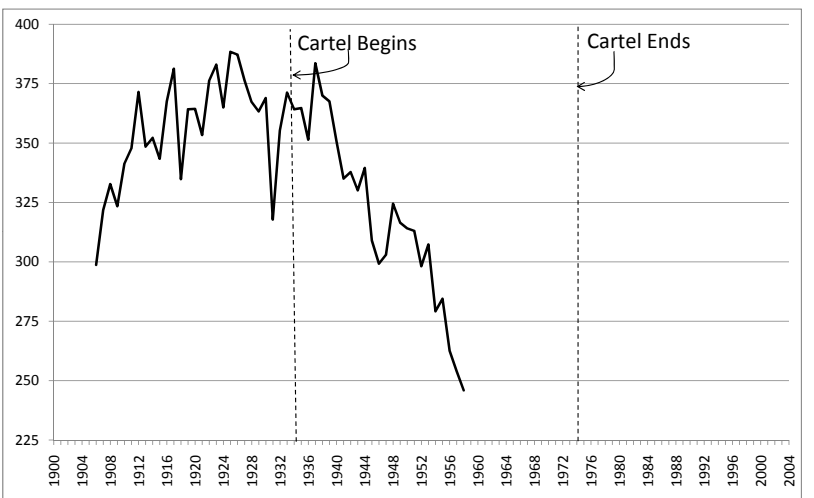

Missoula, MT (American Crystal)

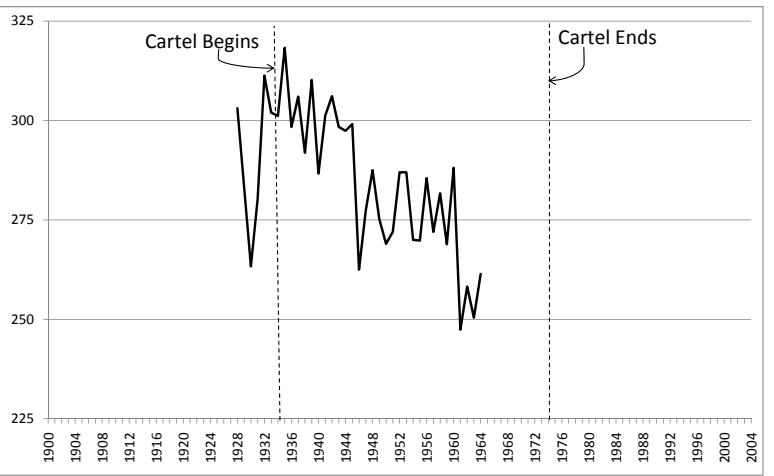

Twins Fall, ID (Amalgamated)

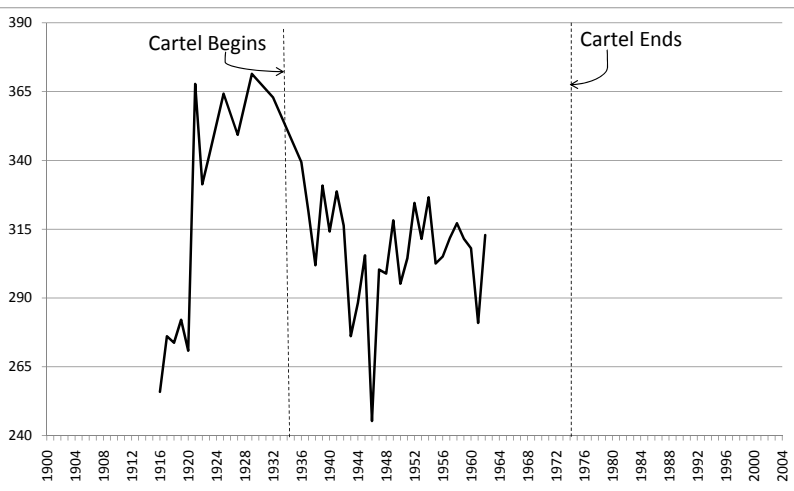

Clarksburg, CA (American Crystal)

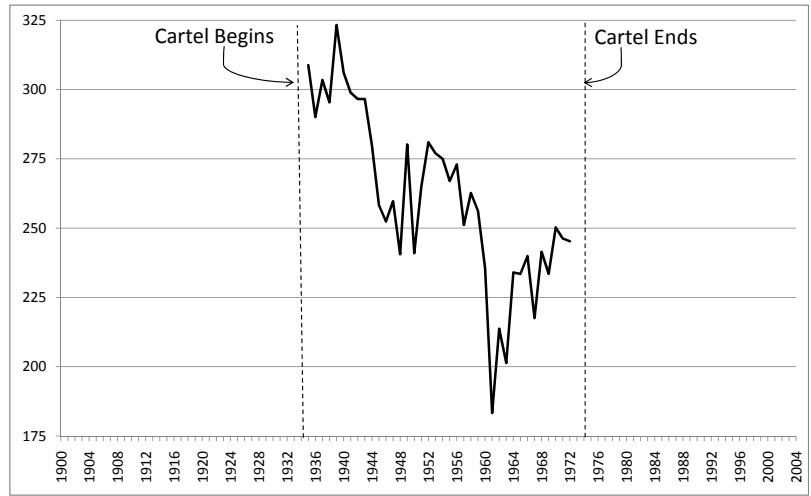

Billings, MT (Great Western)

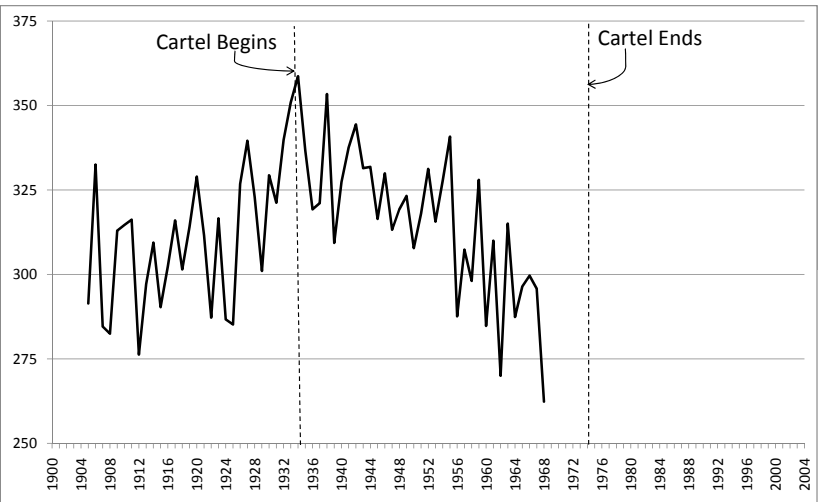

Nampa, ID (Amalgamated)

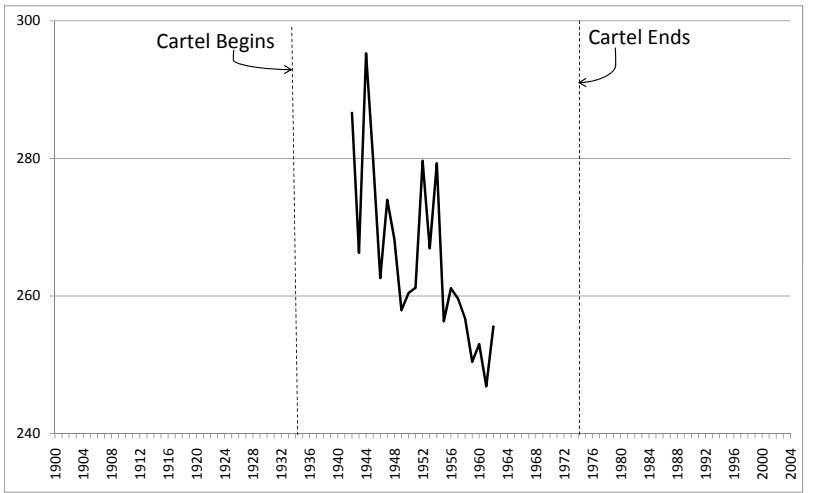

Spreckels \#1, CA (Spreckels)

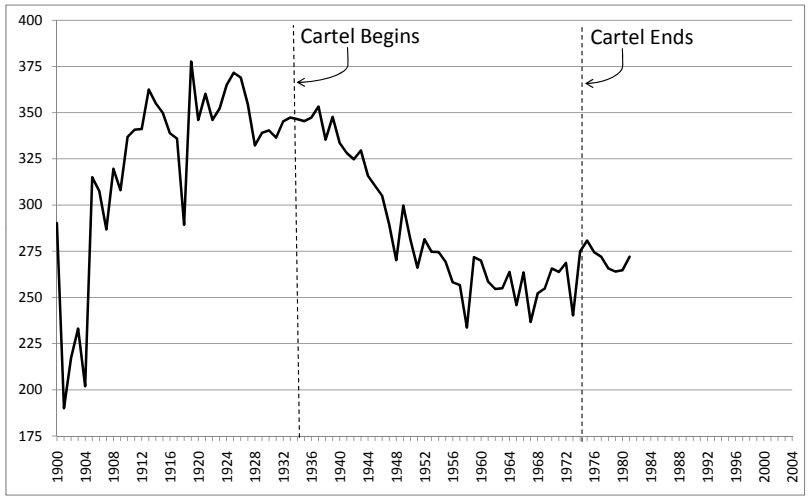

Lovell, MT (Great Western)

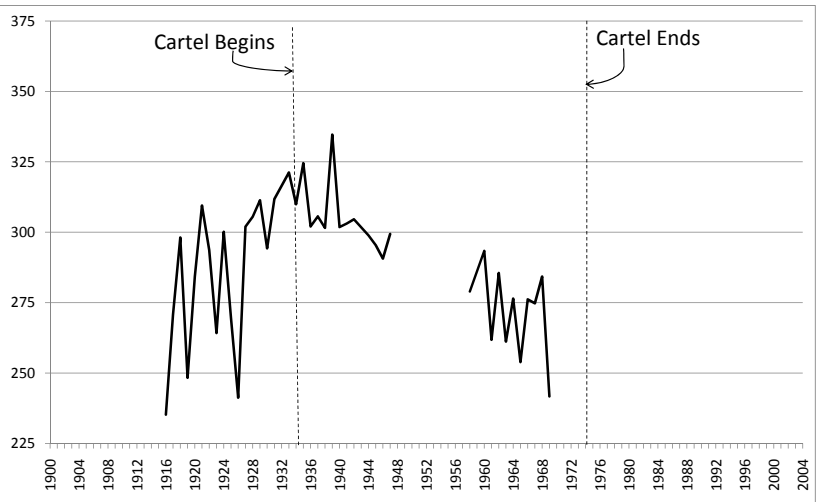

Nyssa, ID (Amalgamated)

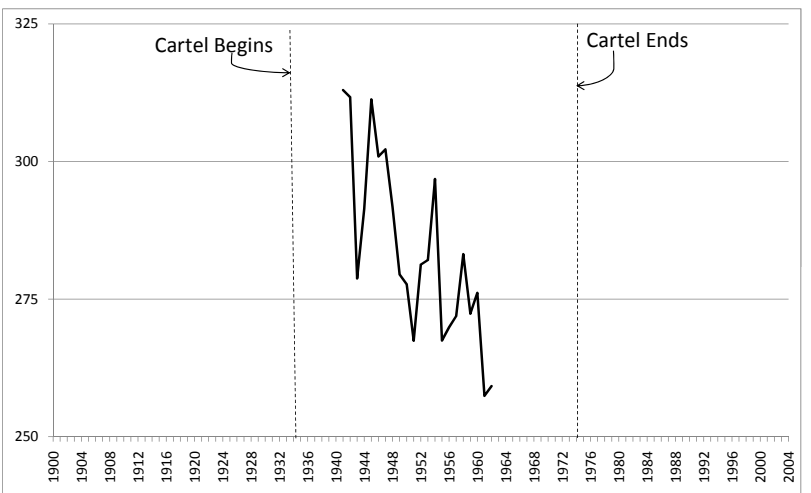




\section{Figure 9B}

\section{Pounds of Manufactured Sugar Per Ton of Beets Recovery Rate - Midwest Factories}
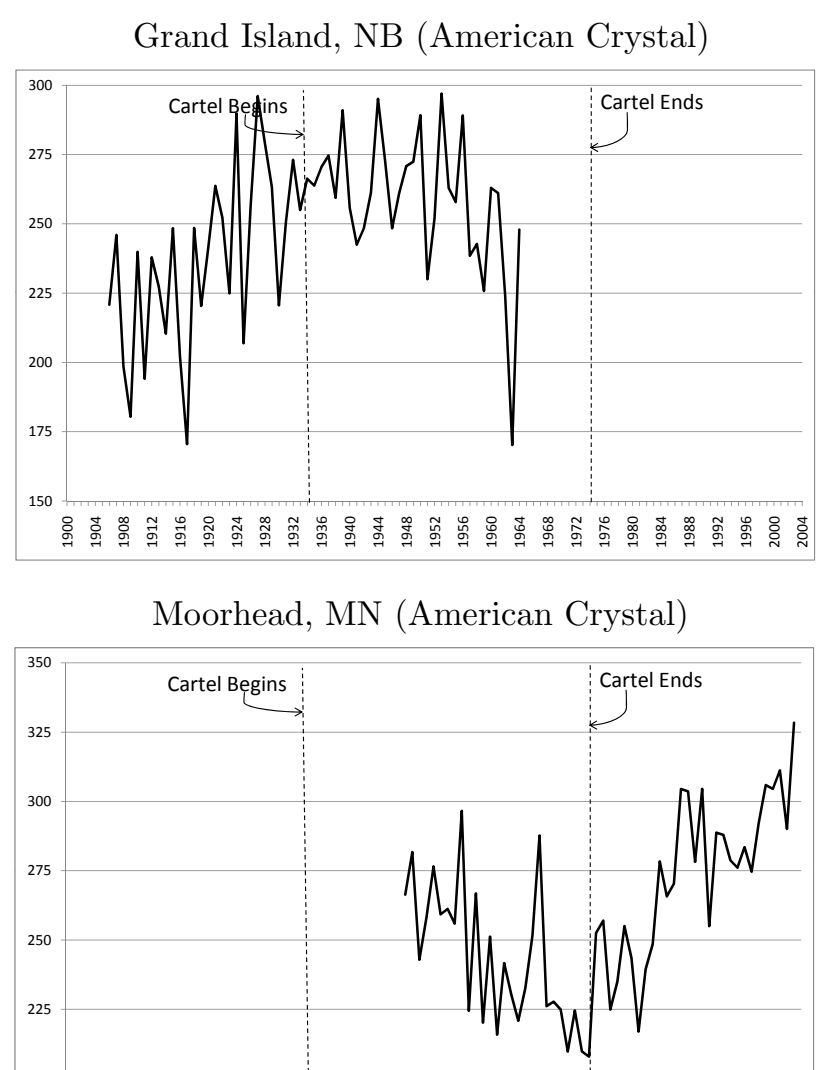

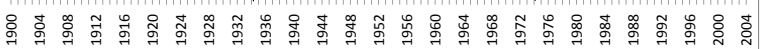

Findlay, OH (Great Western)

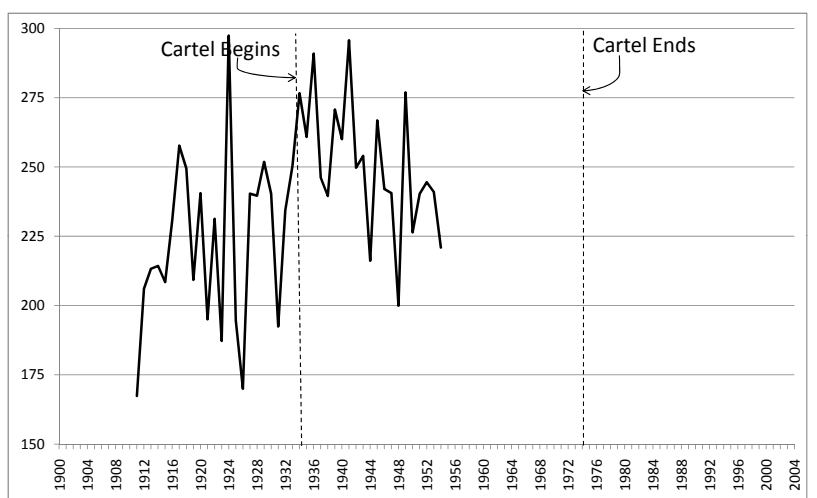

Mason City, IA (American Crystal)

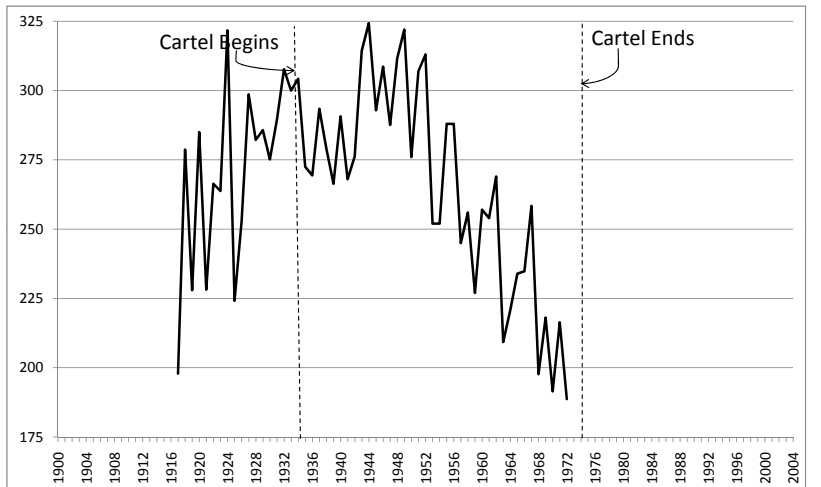

Crookston, MN (American Crystal)

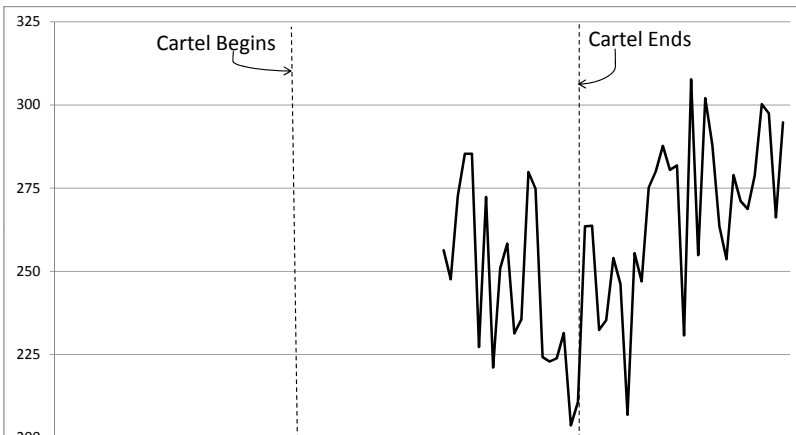

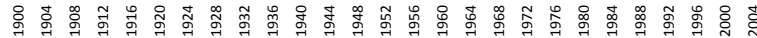

Fremont, OH (Great Western)

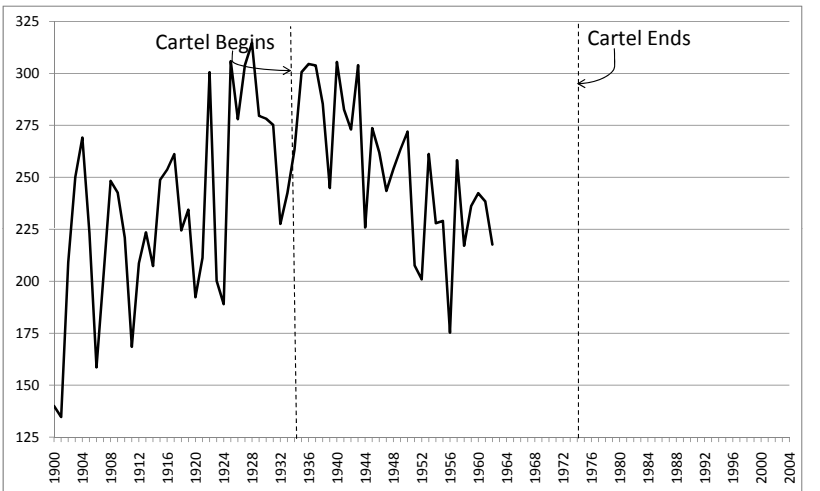

East Grand Fork, MN (American Crystal)

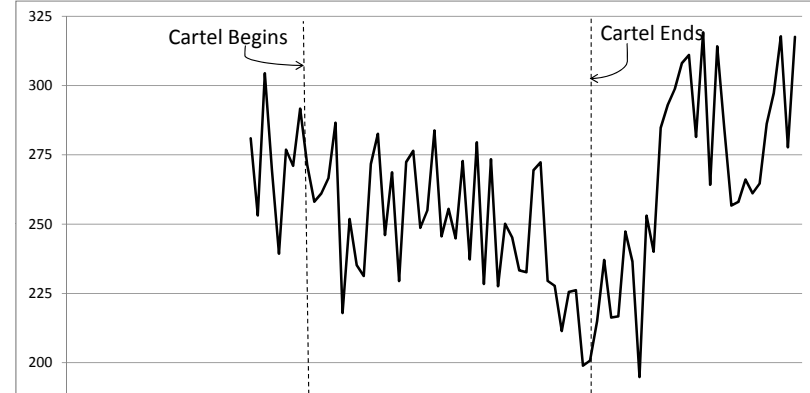

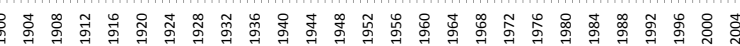

Chaska, MN (American Crystal)

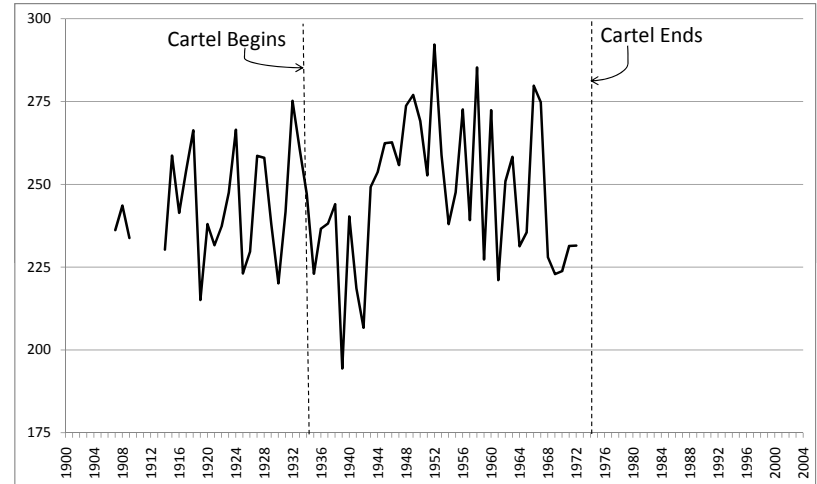

Blissfield, OH (Great Western)

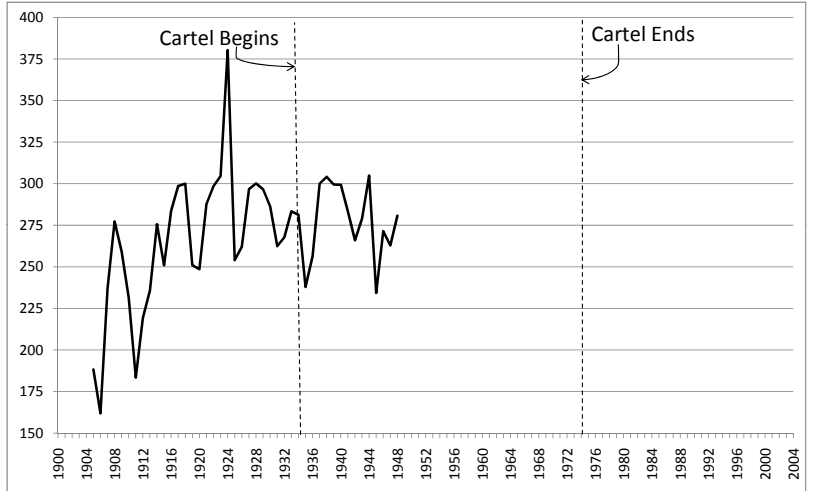


Figure 10

Price of Fertilizer Relative to Price of Land

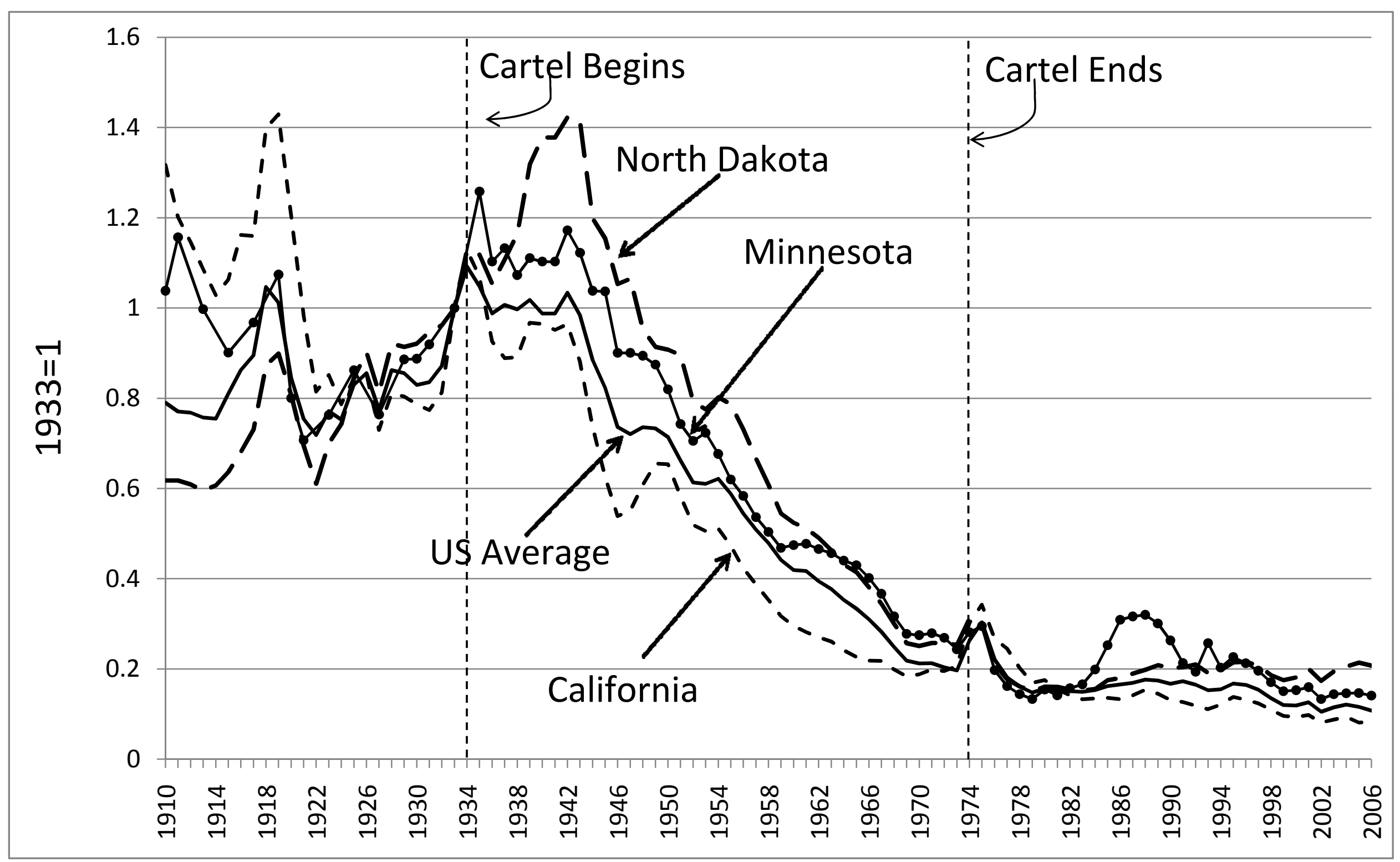


Figure 11

Price of Farmland in California Relative to Price of Farmland in Minnesota and North Dakota

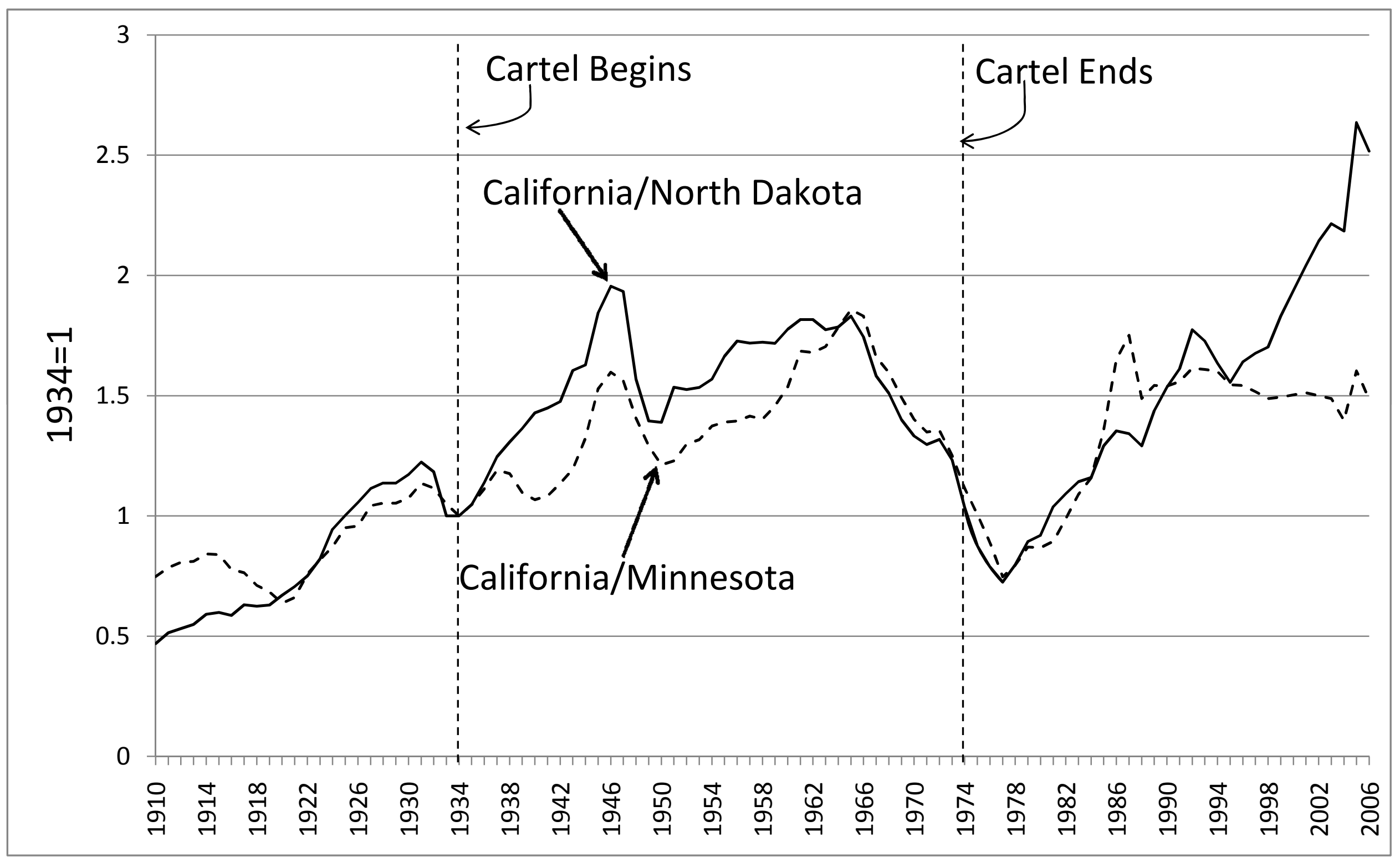


Figure 12

\section{Share of Harvested Acres By Groups of States}

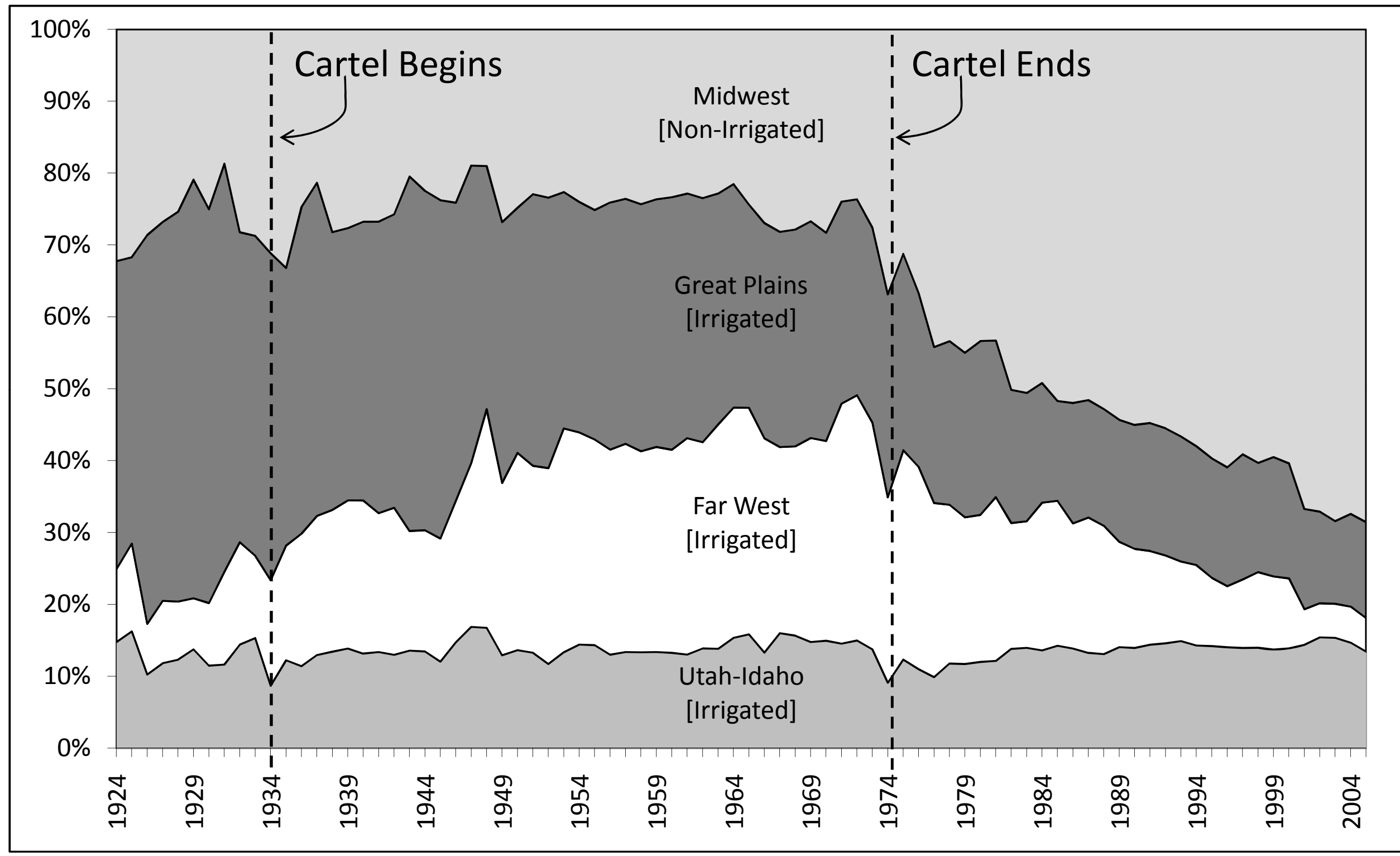


Table 1

Recovery Rate Regressions

\begin{tabular}{|c|c|cc|cc|cc|c|c|}
\hline \multirow{2}{*}{ Region } & Period & Coeff. & S.E. & $\mathrm{t}$ & $P>|t|$ & $95 \%$ Conf. Interval & R-squared & $\begin{array}{c}\text { Number of } \\
\text { Observation }\end{array}$ \\
\hline \multirow{2}{*}{ All Regions } & Before & 1.831 & 0.171 & 10.68 & 0.00 & 1.494 & 2.168 & \multirow{2}{*}{0.522} & 613 \\
& During & -1.357 & 0.301 & -4.51 & 0.000 & -1.948 & -0.766 & & \\
\hline \multirow{2}{*}{ West } & Before & 2.336 & 0.217 & 10.77 & 0.00 & 1.909 & 2.764 & \multirow{2}{*}{0.786} & 216 \\
& During & -2.943 & 0.322 & -9.13 & 0.00 & -3.578 & -2.307 & & \\
\hline \multirow{2}{*}{ Midwest } & Before & 2.877 & 0.290 & 9.92 & 0.00 & 2.306 & 3.447 & \multirow{2}{*}{0.457} & 256 \\
& During & 0.765 & 0.476 & 1.61 & 0.109 & -0.170 & 1.701 & & \\
\hline \multirow{2}{*}{ California } & Before & 0.975 & 0.270 & 3.61 & 0.00 & 0.439 & 1.511 & \multirow{2}{*}{0.744} & \multirow{2}{*}{105} \\
& During & -4.485 & 0.403 & -11.13 & 0.00 & -5.284 & -3.685 & & \\
\hline
\end{tabular}

Note: These are weighted OLS regressions (where tons of beets are the weights). In these regressions, the California region consists of the Oxnard and Clarksburg factories of the American Crystal Company, as well as the Spreckels \# 1 factory; the West region consists of the California factories, as well as the Missoula factory of the American Crystal Company, the Amalgamated Sugar Company and the Utah \& Idaho Sugar Company; the Midwest region consists of the Grand Island, Chaska, East Grand Forks, Moorhead, Crookston and Mason City factories of the American Crystal Company, the Findlay, Fremont and Blissfield factories of the Northern Ohio Company (a subsidiary of the Great Western Sugar Company), and the Michigan Sugar Company; the "All" region consists of the factories and companies listed above and the Great Western Sugar Company. 
Table 2

\section{Pounds of Sugar Gained Per Year Per Ton of Beets} By Region and By Time-Period

(95\% Confidence Intervals in Parentheses)

\begin{tabular}{|c|c|c|c|c|}
\hline & All Regions & West & Midwest & California \\
\hline Period 1 1901-1933 & 1.831 & 2.336 & 2.877 & 0.975 \\
Before Cartel & $(1.494,2.168)$ & $(1.909,2.764)$ & $(2.306,3.447)$ & $(0.439,1.511)$ \\
\hline Period 2 1934-1950 & -1.357 & -2.943 & 0.765 & -4.485 \\
During Cartel & $(-1.948,-0.766)$ & $(-3.578,-2.307)$ & $(-0.170,1.701)$ & $(-5.284,-3.685)$ \\
\hline
\end{tabular}

Note: These are summary statistics from Table 1. 